NBER WORKING PAPER SERIES

\title{
COMPETITIVE EFFECTS OF FEDERAL AND STATE OPIOID RESTRICTIONS: EVIDENCE FROM THE CONTROLLED SUBSTANCE LAWS
}

\author{
Sumedha Gupta \\ Thuy D. Nguyen \\ Patricia R. Freeman \\ Kosali I. Simon \\ Working Paper 27520 \\ http://www.nber.org/papers/w27520
NATIONAL BUREAU OF ECONOMIC RESEARCH
1050 Massachusetts Avenue
Cambridge, MA 02138
July 2020

This research was supported in part by the National Institute on Drug Abuse grant R01 DA039928 (PI: Perry) and the Indiana University Grand Challenges Initiative. We thank Rosalie Pacula, David Powell, Coady Wing and seminar participants at the January 2020 Allied Social Sciences Association (ASSA) meetings and the Indiana University Health Policy Workshop for useful input. We are especially grateful to David Bradford for making additional data available. The views expressed herein are those of the authors and do not necessarily reflect the views of the National Bureau of Economic Research.

At least one co-author has disclosed a financial relationship of potential relevance for this research. Further information is available online at http://www.nber.org/papers/w27520.ack

NBER working papers are circulated for discussion and comment purposes. They have not been peer-reviewed or been subject to the review by the NBER Board of Directors that accompanies official NBER publications.

(C) 2020 by Sumedha Gupta, Thuy D. Nguyen, Patricia R. Freeman, and Kosali I. Simon. All rights reserved. Short sections of text, not to exceed two paragraphs, may be quoted without explicit permission provided that full credit, including $(\subset)$ notice, is given to the source. 
Competitive Effects of Federal and State Opioid Restrictions: Evidence from the Controlled Substance Laws

Sumedha Gupta, Thuy D. Nguyen, Patricia R. Freeman, and Kosali I. Simon

NBER Working Paper No. 27520

July 2020

JEL No. I1,I11,I18,I28

\begin{abstract}
A large concern in U.S. opioid policy is whether supply side controls are effective at reducing the quantity of opioids prescribed, without harmful substitution. An unstudied way that policy targeted a major opioid through the federal Controlled Substance Act (CSA) was the August 2014 scheduling of tramadol products, the second most popular opioid medication at the time. Twelve states implemented the identical policy prior to federal action, providing a unique opportunity to compare effectiveness of the same opioid policy at state versus federal levels. This is important because many recent opioid policy interventions have only taken the form of state actions, while federal policy has largely been advisory. Seven weeks after tramadol's scheduling, the leading opioid form on the market, hydrocodone combination products, was move to the more restricted level II (no refills allowed) from level III in the CSA, allowing us to test a new question in the opioid literature: competitive spillover effects from regulations targeting one drug. Using weekly prescription data spanning 2007-2017, this study finds that tightening prescribing restrictions on one opioid leads to decreases in its use, but also causes some increases in prescriptions of close competitors, leading to no statistically detectable short-run reduction in total opioid prescriptions.
\end{abstract}

\author{
Sumedha Gupta \\ Department of Economics \\ Indiana University-Purdue \\ University Indianapolis \\ 425 University Blvd. \\ Indianapolis, IN 46202 \\ sugupta@iupui.edu \\ Thuy D. Nguyen \\ Indiana University \\ Bloomington, IN 47401 \\ thdnguye@indiana.edu
}

\author{
Patricia R. Freeman \\ Department of Pharmacy Practice \\ $\&$ Science \\ University of Kentucky \\ Lexington, KY 40536 \\ trish.freeman@uky.edu
}

Kosali I. Simon

O'Neill School of Public and

Environmental Affairs

Indiana University

1315 East Tenth Street

Bloomington, IN 47405-1701

and NBER

simonkos@indiana.edu 


\section{Introduction}

Evidence of substitution between prescription and illicit sources of opioids is well established in the literature, (e.g. Alpert et al. (2018); Evans et al. (2019)), showing that policies to limit supply, such as introduction of abuse-deterrent versions of opioids (which make misuse less possible) may lead to consumer-side substitution towards products which have not become harder to obtain, and in the case of Oxycontin reformulation, results in deaths due to heroin.

However, there is relatively little attention in the literature to substitution possibilities between prescription drugs. If such behavior occurs, this weakens the reach of policies that attempt to reduce harms from opioid use in general, but perhaps not as much as when substitution occurs only towards the illicit market. To address this need in the literature, we take advantage of a series of federal policies in 2014 that changed the competitive dynamics between two dominant products in the opioid market. We analyze these with detailed weekly data on prescriptions from a private claims data base as well as from a federal database (Automated Reports and Consolidated Orders System; ARCOS) recently released through a U.S. District Court. The supply restriction policies we study concern tramadol, and hydrocodone combination products (HCPs), the two most commonly prescribed opioid analgesics in the country, contributing roughly 15 and 46 percent of the total US opioid sales respectively since 2012 (IMS Health, 2012).1 Following increasing trends in all opioids, HCP prescriptions increased from 124.1 million to 136.7 million and tramadol product prescriptions climbed from 23.3 million in 2008 to 44 million between 2008-2013 (DEA, 2018).

Perhaps unsurprisingly, related emergency department visits involving misuse of HCPs and tramadol also increased in parallel by 183 and 250 percent, resulting in 97,183 and 21,649 visits respectively in 2011 (Bush, 2015; Report, 2013). According to the National Survey on Drug Use and Health (NSDUH), in 201512.5 million and 1.6 million people in the U.S. population, aged 12 and older, misused HCPs and tramadol products, respectively (DEA,

\footnotetext{
${ }^{1}$ The third is oxycodone with a share of 13.6 percent of the total US opioid sales. HCPs, tramadol and oxycodone products are still 1,2 and 3 as of today, despite the total volume of opioid prescribed having declined substantially in recent years (IQVIA, 2019)
} 
2018).

The active ingredient hydrocodone has been a highly regulated substance since the inception of the Controlled Substance Act (CSA) in 1971, and its pure form is listed with the other commonly prescribed opioid analgesics including oxycodone (e.g. OxyContin) and morphine (e.g. MS Contin) in the CSA schedule II. However, the majority of hydrocodone occurs in combination with non-opioid substances like acetaminophen (e.g. Vicodin) which had remained controlled according to Schedule III, with fewer restrictions on prescribing. In light of mounting suspicion of HCP misuse, the U.S. Drug Enforcement Agency (DEA) requested the U.S. Department of Health and Human Services (HHS) at least twice (2004 and 2009) for a scientific and medical evaluation of available information and a scheduling recommendation for HCPs. On both occasions the HHS recommended to the DEA that HCPs remain controlled by schedule III of the CSA. 22 Similar beliefs about the limited addiction liability of tramadol and its combination products relative to other commonly prescribed opioids (DEA, 2018; Miotto et al., 2017; Babalonis et al., 2013; Zhang and Liu, 2013; Tjaderborn et al., 2009; Zabihi et al. 2011; Zacny, 2005) persisted since tramadol was introduced to the US market in 1995. Consequently, tramadol remained a federally non-controlled prescription drug until 2014.

Following the mounting evidence of tramadol and HCPs misuse, the DEA for the first time scheduled tramadol and its combination products as a Schedule IV (CIV) controlled substance on July 2, 2014, and up-scheduled HCPs to a Schedule II (CII) controlled substance effective October 6, 2014 (DEA, 2014a; DEA, 2014b). These are within-year (within months) changes in policy that could not be separately analyzed without high-frequency data at the weekly level. These changes led to tighter controls on prescribing of tramadol products and HCPs.

The controlled substances policies also give us an opportunity to study the comparative behavioral effects when the same federal opioid restriction is earlier enacted at the state level. State controlled substance acts are communicated and enforced in a similar way as

\footnotetext{
${ }^{2}$ https://www.deadiversion.usdoj.gov/fed ${ }_{r}$ egs/rules/2014/fr0822.htm
} 
federal policy, by the state offices of drug control policy and the inspector general's offices. Delayed federal action lead twelve U.S. States to schedule tramadol combination products as CIV controlled substances within their states between 2007-2014, prior to federal scheduling. New York was the only state to up-schedule HCPs to CII of the CSA in 2013. Refill and prescription length validity rules apply in the same way, regardless of whether it is federal or state level (except that state laws of course only apply to prescriptions filled with state boundaries). Specifically, refills for HCPs were prohibited, and initial prescriptions could not be filled after 60 days from being written, and can cover at maximum 90 days worth of medication. Thus any subsequent prescription requires a doctor to call in a new prescription, which often involved a new visit. As a CIV controlled substance, tramadol prescriptions became valid for up to 6 months after being written and up to 5 refills were allowed within 6 months of original prescription, with subsequent fills requiring a new prescription. Also, as a controlled substance, in some states tramadol could no longer be prescribed by non-physician practitioners due to scope-of-practice laws.

No previous study we are aware of has examined the impact of tramadol scheduling, either at the state or federal level. In the case of supply side state laws such as the heavily studied PDMPs, days limits, pain clinic laws, and marijuana availability laws, there is no federal version for comparison. The tramadol scheduling law is thus a unique case as it was first enacted at the state level and then at the federal level, in identical form ${ }^{3}$ Previous descriptive research suggests that federal up-scheduling of HCPs is associated with decreases in its prescribing (Jones et al., 2016; Bernhardt et al., 2016; Fleming et al., 2017; Gudin and Lee, 2013; Murimi et al., 2019; Northrup et al., 2019); a similar finding occurs in the first economic study of HCPs' up-scheduling (Beheshti, 2019), which finds improved labor market conditions in areas with baseline high intensity of HCP reliance. However, there is no study to date that examines the spillover hypothesis to the closest competitor, tramadol. Further,

\footnotetext{
${ }^{3}$ Often federal health laws are considerably stronger than state laws, for example, in the case of health insurance policy for young adults or contraceptive mandates that were nationally part of the Affordable Care Act but existed in weaker forms in some states prior to that. Although there have been drug-specific federal opioid laws (e.g. Oxycontin reformulation) we are not aware of studies of prescriptive spillovers to other unaffected drugs.
} 
no economic study to date has examined how controlled substance laws affect outcomes at the prescriber level, which allows examining extensive and intensive margins (whether prescribes at all, and strength or days of prescribing) and heterogeneity by provider characteristics. Thus, no study to date has assessed changes in prescribing at the intensive or extensive margins that may result from initial scheduling of a previously non-scheduled medicationtramadol- or compared the relative responses to state- versus federal-level (up-)scheduling of medications, nor the spillover effects when two close competitor products in the opioid market experience restrictions controlling their supply.

A larger literature in economics considers the spillovers from negative information on competitor products in pharmaceutical markets (e.g. Cawley and Rizzo (2008); Collins and Tennyson (2013); Bala et al. (2017); Bütikofer et al. (2020); Daysal and Orsini (2015); Romley and Shih (2017)), and in non-medical markets (e.g. Freedman (2012); Toledo and Villas-Boas $(2019))$.

The closest past literature in medical spillovers is likely in the COX-2 selective nonsteroidal anti-inflammatory drug (NSAID) market, where Vioxx, the most popular product at the time, was voluntarily withdrawn at FDA's request, following evidence of heart attack health harms. Collins and Tennyson (2013) finds that consumers switched to other medications in the class (such as the close competitors Celebrex and Bextra) and to to a closely related other class (analgesics). Six months later, Bextra was withdrawn at FDA's request following further studies, at which point demand dropped for all NSAIDs. Thus, past literature and theory suggests that consumers do not always react to a change in supply restriction on one product by switching to the closest competitor products, if they perceive the negative information as indicating health risks about the product class in general.

There is also a very large literature on the effects of restrictions on all prescription opioids, which by definition cannot examine any substitution within the category. These include PDMPs and pill mill laws, and a variety of other lesser studied state policies.

While earlier PDMP studies found mixed results (eg Meara et al. 2016 find no change in various measure of opioid use after adoption of a PDMP, but Kilby 2016 finds a $12 \%$ decline in 
opioid related mortality following a PDMP), more recent research has distinguished between mandatory and non mandatory PDMPs and find that mandatory policies are effective at reducing prescription opioid misuse (Deiana and Giua, 2018; Bao et al., 2018; Mallatt, 2018; Buchmueller and Carey, 2018a; Grecu et al., 2019; Ali et al., 2017; Ziedan and Kaestner, 2020; Kaestner and Ziedan, 2019; Wen et al., 2019). There is also evidence that even if there is no prior opioid use to query in the system, prescribers may reduce use because of the hassle cost involved or because it has become more salient as a topic (Alpert et al., 2020, Sacks et al., 2019).

Pill mill laws impose stricter policies on pain management clinics that dispense opioids, and appear to have reduced supply Deiana and Giua (2018); Popovici et al. (2018); Ziedan and Kaestner (2020). This suggests that state level policy to restrict opioids have reduced supply. There is a large literature that also studies down stream impacts of these policies. Thus, in the face of this large set of studies, it is a gap in our understanding that there is as yet only a small literature on federal or state level CSA restrictions.

Using quasi-experimental designs, this study proceeds as follows: we first examine how the up-scheduling of HCPs to a CII controlled substance and initial scheduling of tramadol as a CIV controlled substance have changed their own prescribing. Second, we examine the spillover effects of controlled substance status change of a drug on the prescribing of similarly controlled and less controlled substitutes, and their consequences for the overall prescription dispensing of opioids. We do this primarily with rich data from private claims data, but conduct confirmatory analysis with federal data that covers other payor types. Third,we compares the effectiveness of federal-level with state-level controlled substance designations in reducing prescribing of controlled drugs. Fourth, we test for heterogeneous responses by fixed vs variable costs of switching by sorting prescribers into quartiles based on their HCPs and tramadol prescribing volume prior to the scheduling changes and examine whether high volume prescribers responded differentially to the scheduling changes than their low volume prescribing counterparts. Finally, we investigate whether prescribers in different medical specialties responded heterogeneously to the scheduling changes, as some specialities 
(pain specialists) might have not changed their informational view on the medications from re-scheduling or may have patients for whom clinical appropriateness of the medications supersede the prescribing transactional costs.

Stricter CSA regulations may operate through multiple economic pathways to influence prescriber behavior. First, the restrictions on refills would require more frequent office interaction with physicians for new prescriptions, which could be burdensome for patients and prescribers. In addition to increasing healthcare utilization (additional office visits), prescribing more strictly controlled substances would impose recurrent operating costs to provide written or electronic prescriptions, log in to and query the state prescription drug monitoring program before prescribing, enter new data and react to existing data. Third, (up-)scheduling may increase prescriber perception of the risks associated with HCP and tramadol use, thereby negatively impacting the prescriber's perception of the net gain from the medication for the patient, and increasing a sense of more dire consequences if now found negligent through prescriber monitoring. Previous research on FDA drug withdrawals, FDA black-box warnings as well as Consumer Production Safety Commission non-prescription products (children's toys) recalls shows that competitors in the same therapeutic class could experience negative spillovers in some settings (Parkinson et al., 2014; Collins and Tennyson, 2013; Freedman, 2012; Cawley and Rizzo, 2008).

In comparison to state-level scheduling changes which may feel somewhat arbitrary, federal CSA regulations may unequivocally signal the salience of the new information, resulting in greater reductions in prescribing through this channel. Unlike in usual cases of state vs. federal laws (e.g. young adults health insurance mandates, or mental health parity laws), CSA policy changes are enforced the same (direct pharmacy inability to refill) in both cases.

Our main data source is Optum's de-identified Clinformatics ${ }^{\circledR}$ Data Mart system, a comprehensive commercial and Medicare Advantage claims database. Our empirical analysis utilizes claims data covering all states, from January 2007 to December 2017, and regression discontinuity designs to study both national and state policy changes. In sensitivity analysis for the state analysis, difference-in-difference event study methods are used to confirm the 
robustness of our estimates. We find evidence that federal (up-)scheduling of HCPs and tramadol and state-level scheduling of tramadol were associated with significant declines in the prescribing of both opiates, as expected. Our results suggest that both, federal and state-level scheduling changes, are effective in conveying the risk information of a newly (up)scheduled drug. This finding has important implications for state policy. In case of delayed federal action, states can effectively control prescription dispensing of substances with abuse potential through CSA scheduling changes at the state-level.

The majority of the decline in the prescription dispensing of HCP and tramadol was in refills, possibly reflecting the expected reaction to the new prohibition on HCP refills as a CII controlled substance and limits on tramadol refills as a CIV controlled substance. Although the decline in tramadol prescribing was also more concentrated in refills, the decline in initial tramadol prescriptions also substantively contributed to the overall decline in tramadol prescribing. This is also as expected since the tramadol policy change was less stringent regarding refills (CIV: $\max 5$ fills in max 6 month prescription; CII: outright ban on refills).

An important strength of these data is the ability to examine substitution between opioids, given the presence of both HCP and tramadol prescriptions. We find that up-scheduling of HCPs is associated with substantial increases in the prescribing of less regulated opioids (like tramadol), and similarly regulated opioids (like oxycodone). Refills are allowed on schedule III-schedule opioid substitutes, which lowers the variable cost per prescription for these less regulated alternatives. And the other schedule II opioids that HCPs joined were just as costly to prescribe as HCPs. However, in absence of less regulated opioid substitutes to tramadol, we find only weak evidence of substitution away from tramadol following its scheduling. Overall, the decline in the prescription dispensing of HCPs and tramadol following their (up)scheduling was entirely offset by the increase in prescribing of other opioid alternatives, resulting in no net decline in the combined volume of all opioids dispensed. Although tramadol is not available in ARCOS data, we use the newly available weekly level ARCOS data to establish that the changes we see in Optum for other drugs are reflected in multi-payer sources, suggesting that the patterns we see are not limited to private prescrip- 
tions. Our results suggest that Controlled Substance Act scheduling of drugs, particularly at the federal level, is effective in curbing excessive prescribing of drugs with known dependence and misuse potential, but as found in other contexts, there are unintended substitution behaviors that may unravel the deeper intention of the policy.

\section{Background and conceptual framework}

Title 21 of the United States Code Controlled Substances Act (CSA) regulates substances based on three criteria - established medical use, potential for misuse and dependence liability (DEA, 2018b). The Drug Enforcement Administration (DEA), the Food and Drug Administration (FDA) and the Department of Health and Human Services (HHS) are the agencies responsible for gathering evidence to support controlled designation of a substance and initiating legislation for its scheduling as a controlled substance. Based on the criterion measures, designated controlled substances are placed in one of the five CSA schedules, in descending order of control. Irrespective of whether the stricter CSA scheduling of a substance was at the federal or state level, upon controlled substance designation, each drug (schedule) class mandates restrictions on the manufacturing, importation, distribution, prescribing, possession and use of the scheduled substance, and the penalties for their violation. Consequently, following HCPs' up-scheduling to Schedule II, HCP prescriptions were now valid for only ninety days after being written, and refills of HCPs were prohibited, with any subsequent fill requiring a patient visit to receive a new prescription (see Table 1). As a Schedule IV control substance, tramadol prescribing was relatively less controlled, with prescriptions valid for up to 6 months after being written and no more than 5 refills allowed within 6 months of original prescription, and again subsequent fills requiring a new prescription.

(Up-)scheduling of HCPs and tramadol as Schedule II and IV controlled substances, respectively, may inform prescriber behavior in several ways. First, (up-)scheduling may generally increase prescriber perception of the risks associated with HCP and tramadol use, 
Table 1: Characteristics and Regulations: Schedule Tiers under the U.S. Drug Enforcement Agency Controlled Substance Act.

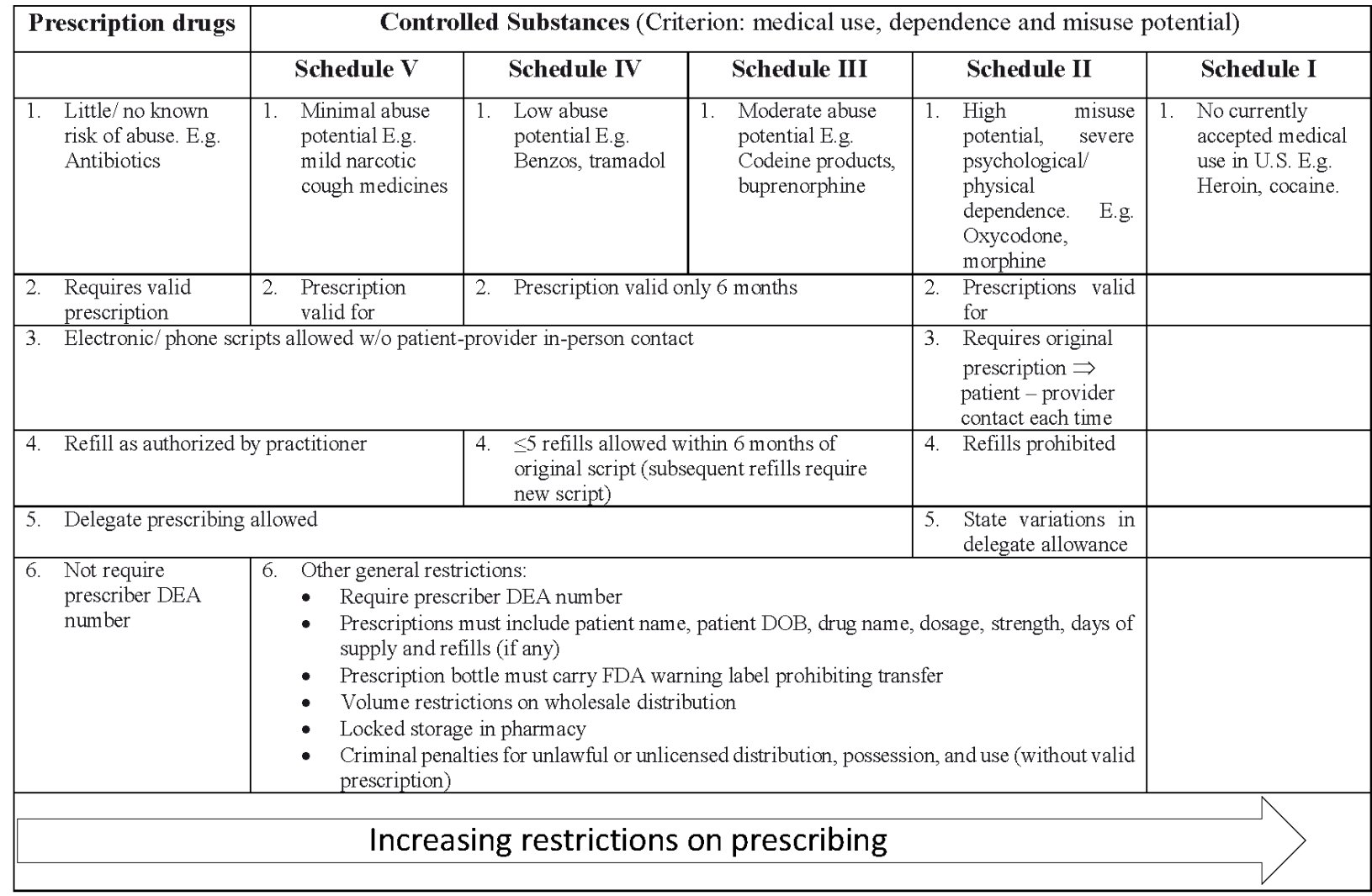

thus revising downwards the perceived net benefit to the patient by the provider (and possible also through a patient's own information). For instance, earlier literature on the impact of 'black box' warnings issued by the Food and Drug Administration for certain drug classes finds that consumers/providers take such warnings to signal extra risk, leading to significant declines in the use of those drugs (Parkinson et al. 2014). This effect may be greater in case of federal scheduling changes, while selective state actions may seem more arbitrary. Second, new restrictions on refills would require new prescriptions, which could be burdensome for patients and prescribers, reducing the total number of claims observed in our data. In addition to increasing healthcare utilization (additional office visits and prescriptions), patients could be subject to longer wait times to receive their medication and additional office visits would entail transportation and parking costs, co-pays and lost time from work Gudin and Lee, 2013). To avoid these added costs, prescribers may switch patients to non-opioid analgesic 
substitutes with reduced efficacy or increase the length or strength of initial prescriptions and permitted refills, or switch patients to more potent analgesic substitutes with the intention of spreading dosage over a longer duration. Higher dosages and longer use of opioids which could result from longer duration prescriptions, elevate the patient's risk of developing an opioid-use disorder (Dowell et al., 2016a) and could be an unintended consequence of up-scheduling. Alternatively, an intended outcome of the frequent patient-provider contact could be recurrent reevaluations of the pain condition and timely termination of opioid therapy.

The effects of (re-)scheduling maybe heterogeneous for many different groups. For one, it may differ by baseline prescribing rates of HCPs or tramadol among providers and by specialty of provider: those with more familiarity with a drug may respond less to the informational content, and providers may behave differently for existing patients than for new patients, or for patients with more severe chronic pain. Fourth, in case of tramadol converting to controlled substance status, prescribing is restricted to practitioners with a valid DEA license numbers (in a state that allows nurse practitioner prescribing) and may eliminate prescribing by nurse practitioners, resulting in an overall decline in tramadol prescribing. Finally, stricter CSA scheduling may have an overall 'chilling effect' on the prescribing of HCPs and tramadol; if they perceive greater risks of the medication, they maybe more hesitant to amass a record of its prescribing.

The timeline of state and federal scheduling changes of HCPs and tramadol is presented in Figure 1. Between 2007-2014, and prior to tramadol's federal scheduling, 12 U.S. States - Arkansas, Georgia, Illinois, Kentucky, Mississippi, New Mexico, New York, North Dakota, Oklahoma, Tennessee, Wyoming and Ohio - designated tramadol as a Schedule IV controlled substance. At the time of scheduling tramadol as a controlled substance, the state of New York also up-scheduled HCPs to a Schedule II controlled substance. The U.S. DEA federally scheduled tramadol as a Schedule IV controlled substance on August 18, 2014 and seven weeks later on October 6, 2014, up-scheduled HCPs to Schedule II. Within state boundaries, state-level scheduling changes have similar actual enforcement as federal-level scheduling. 
However, previous literature examining other state opioid policies that have restricted opioid prescribing has noted that misuse responds to declines in the opioid prescribing by aggressively engaging in cross state border 'doctor shopping' for prescriptions in neighboring states that have not implemented similar regulations (Buchmueller and Carey, 2018b). Consumers may also perceive greater salience of the risks inherent in the medications if the action is at the federal level. In case state-level scheduling of medication is thwarted by similar non-compliance, we expect federal scheduling to have a larger magnitude effect on the prescription dispensing of the affected drugs.

\section{Data}

\subsection{Data Sources}

Changes in prescription dispensing of HCPs and tramadol following the scheduling changes are examined using Optum's de-identified Clinformatics ${ }^{\circledR}$ Data Mart system, a comprehensive commercial and Medicare Advantage claims database. The database includes claims from all enrollees from January 2007 through April 2018. For those who were ever dispensed a controlled substance during the study period $4^{4}$ we obtained detailed information on all claims records ever associated with them. Every state is represented in every month.

We identify prescription dispensing of HCPs and tramadol using the National Drug Code (NDC) and the NDC-active ingredient crosswalk of all prescription opioids, which we obtained from Prescription Drug Monitoring Program Training and Technical Assistance (2013). Different opioids vary in their strengths, thus following earlier literature, all drug strengths have been converted to Morphine Equivalent Doses (MED) (CDC, 2018). Length of a prescription is measured by the number of days of opioid supplied.

Although tramadol products are not contained in the ARCOS system, it does contain HCPs, and also Schedule I, II and some III opioid-based medications (DEA, 2009). The public use version of the data provided by ARCOS is only quarterly and thus not of use for

\footnotetext{
${ }^{4}$ The list of what is considered a controlled substance was determined as of 2017 , thus included tramadol.
} 
Figure 1: Timeline of U.S. Drug Enforcement Agency Controlled Substance Act scheduling changes of HCPs and tramadol.

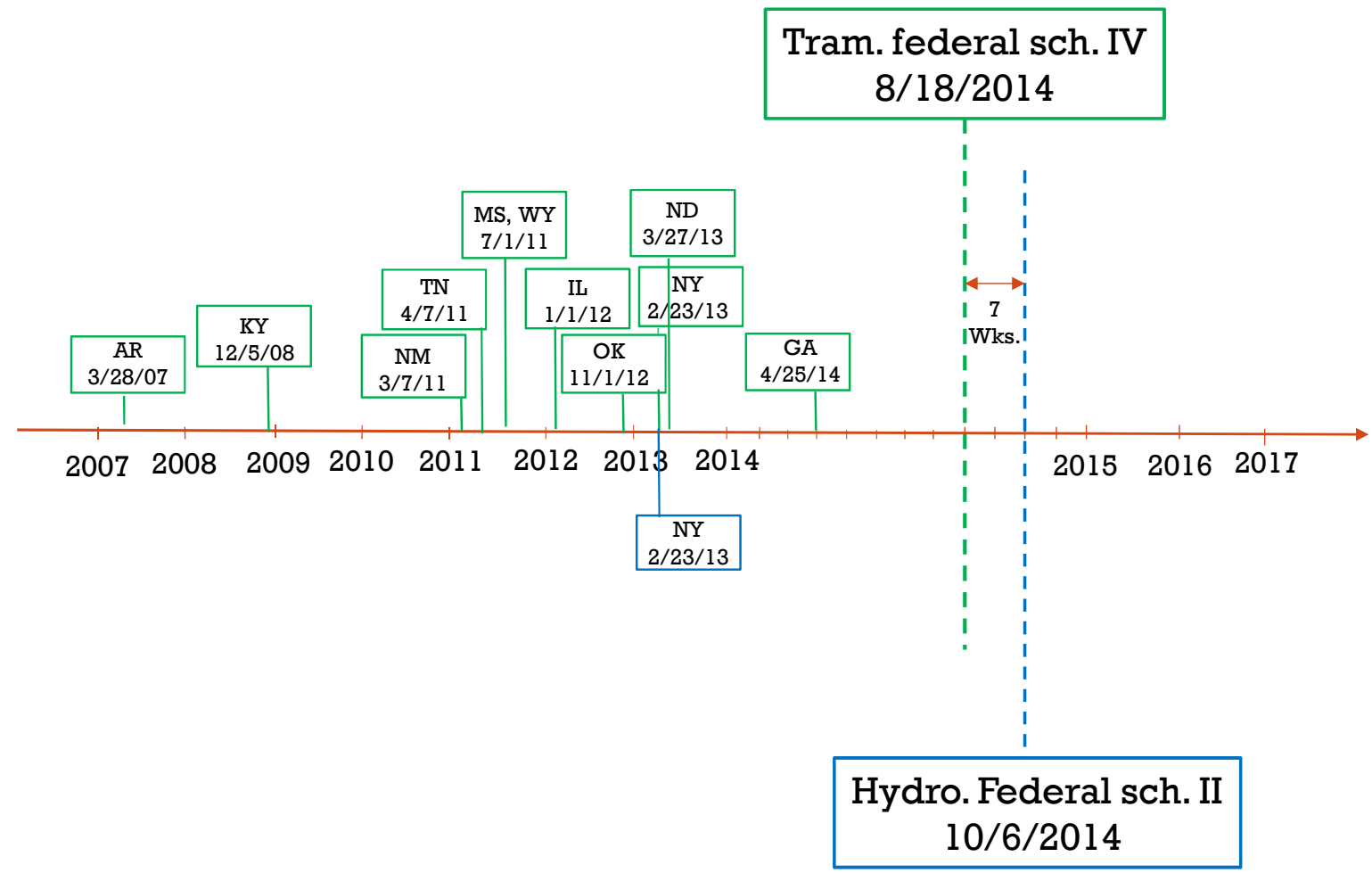

Notes: Authors' compilations based on states' legislation database. See details in Table A1

our study. However, there was a special extract of the data (years 2006-2014) made available through a court order. Transactional (details down to the exact transaction in timing, location and substance NDC) ARCOS data were released in 2018 on order of the United States District Court Northern District of Ohio Eastern Division following the National Prescription Opiate Litigation (Case No. 1:17-MD-2804, UNITED STATES DISTRICT COURT NORTHERN DISTRICT OF OHIO EASTERN DIVISION). This enabled us to make several advances that allows ARCOS data to be useful for our study.First, we are able to obtain a weekly series of total HCP and other opioid morphine milligram equivalent or morphine equivalent dose (MME or MED) for the period, to examine whether the highfrequency trends in HCPs seen in Optum hold up in national data. While we cannot fully tell whether there is a competitive effect as tramadol, the closest competitor, is missing, 
we can look for signs of competitive effects to other medications. The traditional ARCOS cannot separate prescriptions given through community retail pharmacies (the form that is affected by the CSA policy), with those given through hospitals and other institutions. With the detailed transaction level ARCOS that identifies the location, we are able to do that.

We also use Medicaid State Drug Utilization Data as a supplementary data source. These are only at the quarter level, but represent an important specific payor, that includes tramadol (along with all other opioids). Although prior work found modest decreases in rates of HCP use in the elderly following the up-scheduling of HCPs (Kuo et al., 2018), the public use version of the CMS Medicare part D data is only annual and thus we do not use Medicare data for our study.

Our information on effective dates of state-level scheduling of tramadol (homogeneous policies-all are to Schedule IV) is obtained from individual state legislative sources included in Appendix Table A1.

Other data sources for control variables include the Bureau of Labor Statistics for statelevel unemployment rates (BLS, 2018), National Cancer Institute's Surveillance, Epidemiology, and End Results Program for state level demographic information (SEER, 2018), 2010 US Census Bureau for state population rates and percent of rural population in each state, and Area Health Resource File (AHRF) for the number of physicians, physician assistants, and registered nurses per 100,000 in each state. This study also used the following sources for five state-level policies as controls: (1) implementation dates of mandatory PDMPs obtained from Nguyen et al. (2019), (2) implementation dates of the Affordable Care Act(ACA) expansion from the Kaiser Family Foundation (Kaiser Family Foundation, 2019), (3) pain clinic regulations from the Prescription Drug Abuse Policy System (PDAPS) (PDAPS, 2018), (4) medical marijuana laws for patients from PDAPS, and (5) day limit laws from Sacks et al. (2019). The timeline of the other opioid policy adoptions in each of the fifty US states and relevant sources are summarized in Appendix Table A2. 


\subsection{Sample construction}

Estimation of the prescribing changes in response to federal scheduling changes exploits the fact that the exact timing of the federal scheduling changes were unanticipated, immediate, and binding. Tramadol was first scheduled as a schedule IV controlled substance at the federal level on August 18, 2014. This was followed seven weeks later, by the federal upscheduling of HCPs. To stay clear of other scheduling changes, we focus on only a narrow 5-week window around each of the federal action. Specifically, we compare prescribing of the affected drug in the five previous weeks with its prescribing in the five weeks after its federal regulation. Consequently, the study windows are July 13, 2014-September 20, 2014 for tramadol and August 31, 2014-November 8,2014 for HCPs. We restrict the federal analysis of the HCP rescheduling to the 49 states that did not up-schedule HCPs prior to its federal scheduling and the federal tramadol scheduling to the 38 states that has not already acted in a similar manner.

In a separate analysis, we examine the effect of state-level scheduling of tramadol as a schedule IV controlled substance between January 2008-August 2014, and before its federal scheduling on August 18, 2014. The treatment sample for these analyses includes nine of the twelve states - Illinois, Kentucky, Mississippi, New Mexico, North Dakota, Oklahoma, Tennessee, Wyoming and Georgia - that acted on tramadol's status prior to federal law (refer Figure 1). Arkansas is omitted from the analysis as it scheduled tramadol in 2007, prior to the start of our observation window. Although Ohio passed legislation for controlled substance designation of tramadol prior to August 2014, the effective date of implementation of Ohio's ruling was after that. Finally, New York concurrently scheduled tramadol and upscheduled HCPs to a Schedule II controlled substance on the same day, February 23, 2013, making isolation of the two effects difficult and thus is removed from the analysis as well 5

Using the sample of the nine treatment states, centered at the timing of state-level tramadol scheduling, we compare prescribing of tramadol in the five prior weeks to its prescribing

\footnotetext{
${ }^{5}$ New York was the only state to up-schedule HCPs to Schedule II, prior to its federal up-scheduling on October 6, 2014, thus we cannot conduct a state level DD study for HCPs as for tramadol.
} 
in the five weeks after state regulations.

\subsection{Prescribing outcomes}

We constructed four outcomes associated with prescribing in the Optum data. The unit of observation is the prescriber-year-week. Prescribing of HCPs or tramadol is measured as the weekly rate of dispensed prescriptions, the rate of patients prescribed the medications, the average days' supply per prescription, and the average strength of each prescription (in standardized morphine equivalent doses (MED). The weekly rates of prescriptions, and the number of patients prescribed the medications, are created with the denominator being the number of unique patients to whom the prescriber prescribed medications of any type in a week 6

\subsection{Non-parametric analysis}

Figure 2 graphically presents the trends in the four prescribing measures for HCPs (Panel A) and tramadol (Panel B) between April 2013 (starting at week 12 of that year) through April 2016 (week 16 of that year). The first vertical line designates the federal initial scheduling of tramadol on August 16, 2014. The second vertical line represents the federal up-scheduling of HCPs seven weeks later on October 6, 2014. Figure 2, Panel A, shows HCP prescribing (in the 49 states that did not earlier up-schedule HCPs). Similarly Figure 2, Panel B, shows tramadol prescribing trends (in the 38 states that did not earlier schedule tramadol). These plots capture three distinct periods. The first period spans 2013w12-2014w33, before the federal scheduling changes for either drug. During this time, as a CIII opioid, prescribing of HCPs was more restricted than prescribing of tramadol, a non-controlled substance. The second period, 2014w34 - 2014w40, consists of the seven weeks after the federal scheduling of tramadol and before the federal up-scheduling of HCPs, when the prescribing restrictions on

\footnotetext{
${ }^{6}$ Prescribing across all drug classes is available for 60 percent of the prescriber sample. For the remaining prescribers, we approximate number of unique patients as their (number of unique patients with controlled substances/average share of prescription recipients receiving a controlled substance prescription across all prescribers).
} 
both drugs were comparable. Finally, the third period begins after the federal up-scheduling of HCPs, when again, the prescribing of HCPs as a CII substance was much more restricted than that of CIV tramadol.

Several observations emerge from this descriptive analysis. In Figure 2, Panel A we find a fairly flat trend in HCP prescribing between 2013-2016, with a sharp, one-time downward shift in all four prescribing outcomes we study - rate of dispensed prescriptions, rate of patients prescribed, average days' supply per prescription and average MED per prescription in the fourth quarter of 2014, when HCPs were up-scheduled. Although the decline in patients prescribed HCPs and prescriptions of HCPs written persisted, the average days' supply and MED per prescription begins to slowly rise after their immediate decline following the federal HCP policy. From Figure 2, Panel B we note a strong upward trend in tramadol prescribing throughout 2013-2016, with a one-time level increase in prescribing in the fourth quarter of 2014, coinciding with the federal scheduling of HCPs. The level increase in tramadol prescribing in October 2014 is visible for both the extensive and the intensive margin of prescribing but is particularly pronounced at the extensive margin. By 2016, prescription dispensing of tramadol exceeded its pre-scheduling level, with persistent upward trends at the intensive margin of prescribing.

In Figure 2, Panel A, as expected, we do not see any evidence of tramadol's scheduling leading to increases in prescribing of HCPs at the extensive margin, as HCPs would not be viewed as a less regulated substitute. Prescribing of HCPs remained almost steady in between the red lines, until it declines following federal up-scheduling. During the seven week period between the federal scheduling of tramadol and the federal up-scheduling of HCPs, CSA restrictions on prescribing of tramadol and HCPs were the same (as Schedule IV and Schedule III are comparable in this regard (refer Table 1). Thus, prescribers could now consider HCPs and tramadol as substitutes in terms of prescribing costs. If the benefit from prescribing the more potent HCP is sufficiently large, prescribers who were previously treating their patients with tramadol may switch to HCPs. Indeed, in Panel B we see an interesting pattern in between the red lines, that would be missed if we did not have weekly 
data. In this short 7 week period, we detect the immediate decline in tramadol prescribing in response to its federal scheduling, but the decline was not sustained. Tramadol prescribing again began to significantly increase as soon as HCPs were up-scheduled, consistent with tramadol playing the role of a less restricted substitute to HCPs. Quarterly data would show only a consistent increase in tramadol prescribing and miss this substitution pattern, and would make it seem like CSA policy towards tramadol was ineffective. Instead, the story here is consistent with the policy having intended effects of reducing tramadol prescribing, but an unintended but economics-grounded substitution spillover once HCPs became more tightly controlled.

Given evidence that the HCP decline in prescribing following its up-scheduling was accompanied by an increase in prescribing of tramadol at precisely the same time, the next question is, what happened to all opioids as a class? In addition to tramadol, did other less regulated opioids also see spillover increases? We next study aggregate opioid prescription dispensing by measuring total (MED) quantity of all opioids dispensed each week. Figure 3 presents this measure between April 2013 through April 2016. In this descriptive plot, there appears to be no net decline in aggregate total MED quantity of all opioids prescription dispensed as a result of stricter CSA regulations on HCP and tramadol combined.

Next, we examine the effect of state-level initial scheduling of tramadol. Figure 4 plots tramadol prescribing trends in the nine treatment states that designated tramadol as a controlled substance prior to its federal scheduling. We consider a 16 week window surrounding the state-level tramadol scheduling, with the plots centered at the time of the state regulations. The figure presents scatter plots with the lowess regression line for each of the four prescribing outcomes we consider. We find that controlled substance designation of tramadol at the state-level is also associated with an immediate and sharp decline in all measures of tramadol prescribing. Moreover, in absence of other regulatory changes (like the federal up-scheduling of HCPs seven weeks after tramadol's federal scheduling), the decline in tramadol prescribing at the extensive margin following its state-level CSA designation is sustained for longer, in the case of number of patients and number of prescriptions, although 
in both days supply and MED, there appears a rebound that starts after about 5 weeks. A common theme we find in our research is that looking at high-frequency data is necessary for observing effects of the policies. It is not clear why the effects dissipate so rapidly, but using quarterly data (or annual data) would not allow research to uncover these intended effects of the policies. 
Figure 2: National trend in HCP and tramadol prescription dispensing relative to federal scheduling changes.

(Only states without prior state-level (up)scheduling.)

\section{Panel A: HCPs}

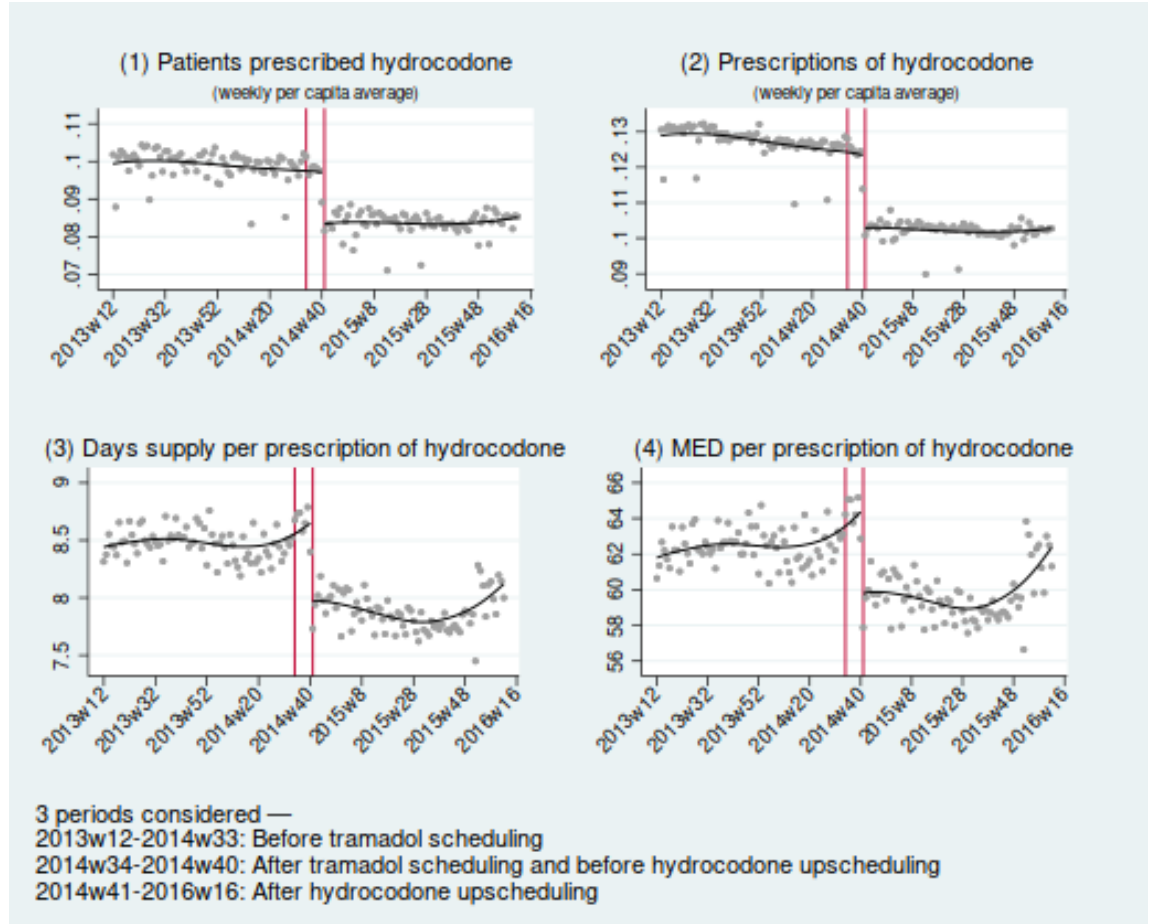

Panel B: Tramadol
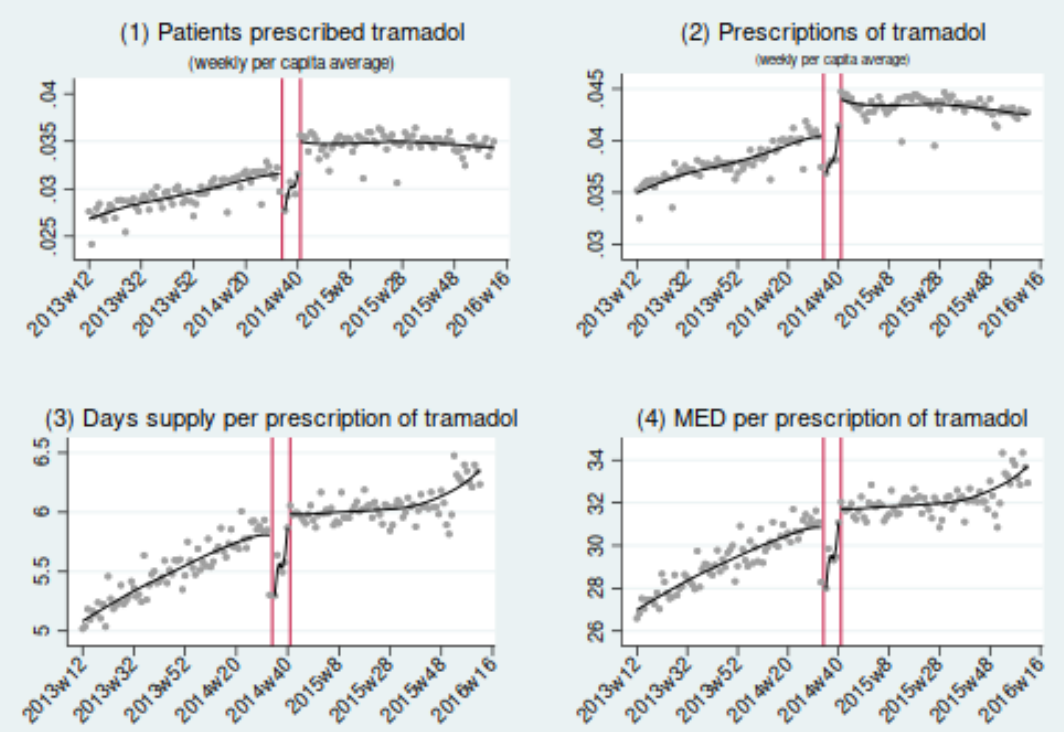

3 periods considered -

2013w12-2014w33: Before tramadol scheduling

2014w34-2014w40: After tramadol scheduling and before hydrocodone upscheduling

2014w41-2016w16: After hydrocodone upscheduling

Notes: Authors' calculations based on Optum's de-identified Clinformatics ${ }^{\circledR}$ Data Mart system, a comprehensive commercial and Medicare Advantage claims database. Unit of observation is prescriber-week. Observation window is April 2013 to April 2016. Panel A plots the prescription dispensing of HCPs and Panel B plots the prescription dispensing of tramadol. Four prescription dispensing outcomes are considered for both drugs - user rates (1), prescription rates (2), average days' supply per prescription (in Days) (3) and average Strength per Prescription (in MED) (4). The number of total patients in the database changes throughout our study period. The data do not report the number of patients enrolled with each prescriber in every week. Therefore, rates of patients prescribed (1) and prescriptions (2) are calculated with a denominator of the total number of unique patients the prescriber prescribed (any opioid or non-opioid drug) to each week. The first vertical line represents the timing of federal initial scheduling of tramadol on August 18,2014. The second vertical line represents the federal up-scheduling of HCPs on October 8, 2014. Prescription dispensing of HCP 9 9nd tramadol is considered in 3 distinct periods: period before the federal initial scheduling of tramadol (2013w12-2014w33), period after the federal initial tramadol scheduling and before the federal HCP up-scheduling (2014w34-2014w40) and the period after both scheduling changes (2014w41-2016w16). 
Figure 3: National trend in total MED prescription dispensed of all opioids relative to federal scheduling changes.

(Only states without prior state-level (up)scheduling.)

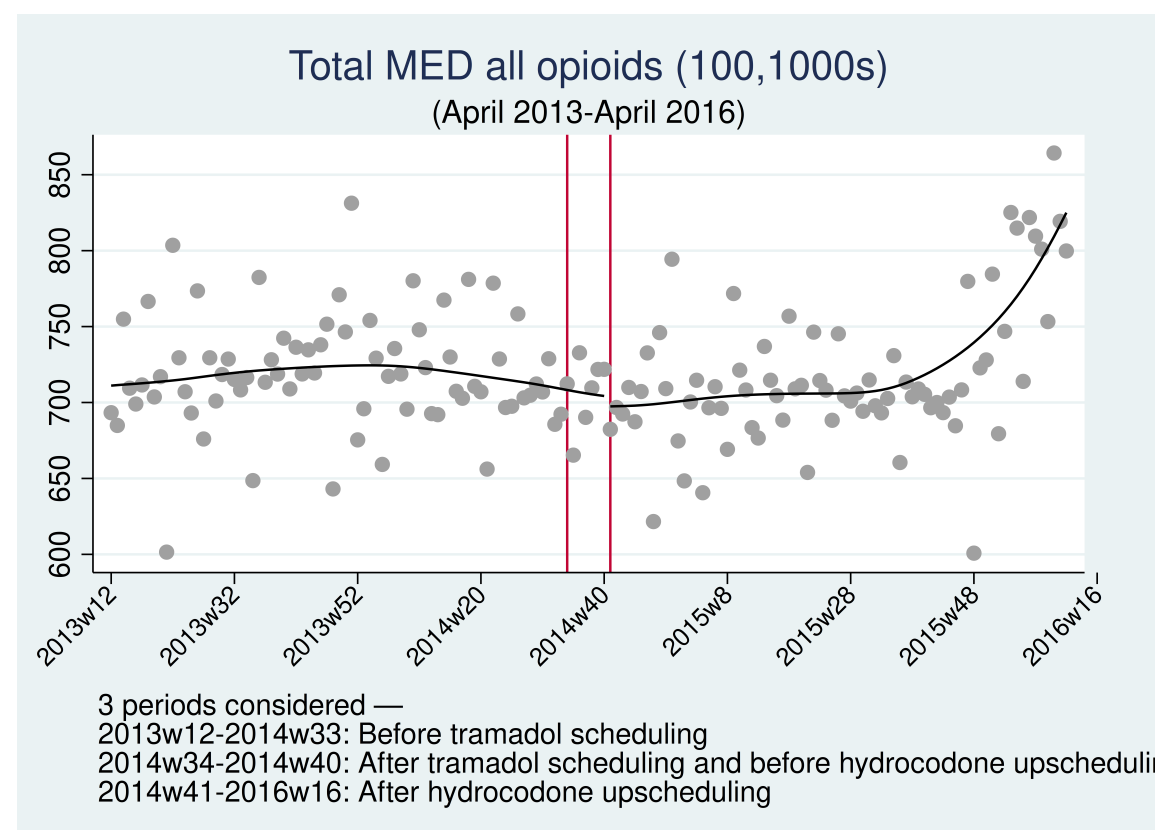

Notes: Authors' calculations based on Optum's de-identified Clinformatics ${ }^{\circledR}$ Data Mart system, a comprehensive commercial and Medicare Advantage claims database. Unit of time is week. The figure plots the total MED quantity of all opioids prescription dispensed between April 2013 to April 2016. The first vertical line represents the timing of federal initial scheduling of tramadol on August 18, 2014. The second vertical line represents the federal up-scheduling of HCPs on October $8,2014$. Prescription dispensing of HCPs and tramadol is considered in 3 distinct periods: period before the federal initial scheduling of tramadol (before 2014w33), period after the federal initial tramadol scheduling and before the federal HCP up-scheduling (2014w34-2014w40) and the period after both scheduling changes (after 2014w41). 
Figure 4: Trend in average weekly tramadol prescription dispensing in the 14-week window surrounding the state-level initial scheduling of tramadol (2007-2013).

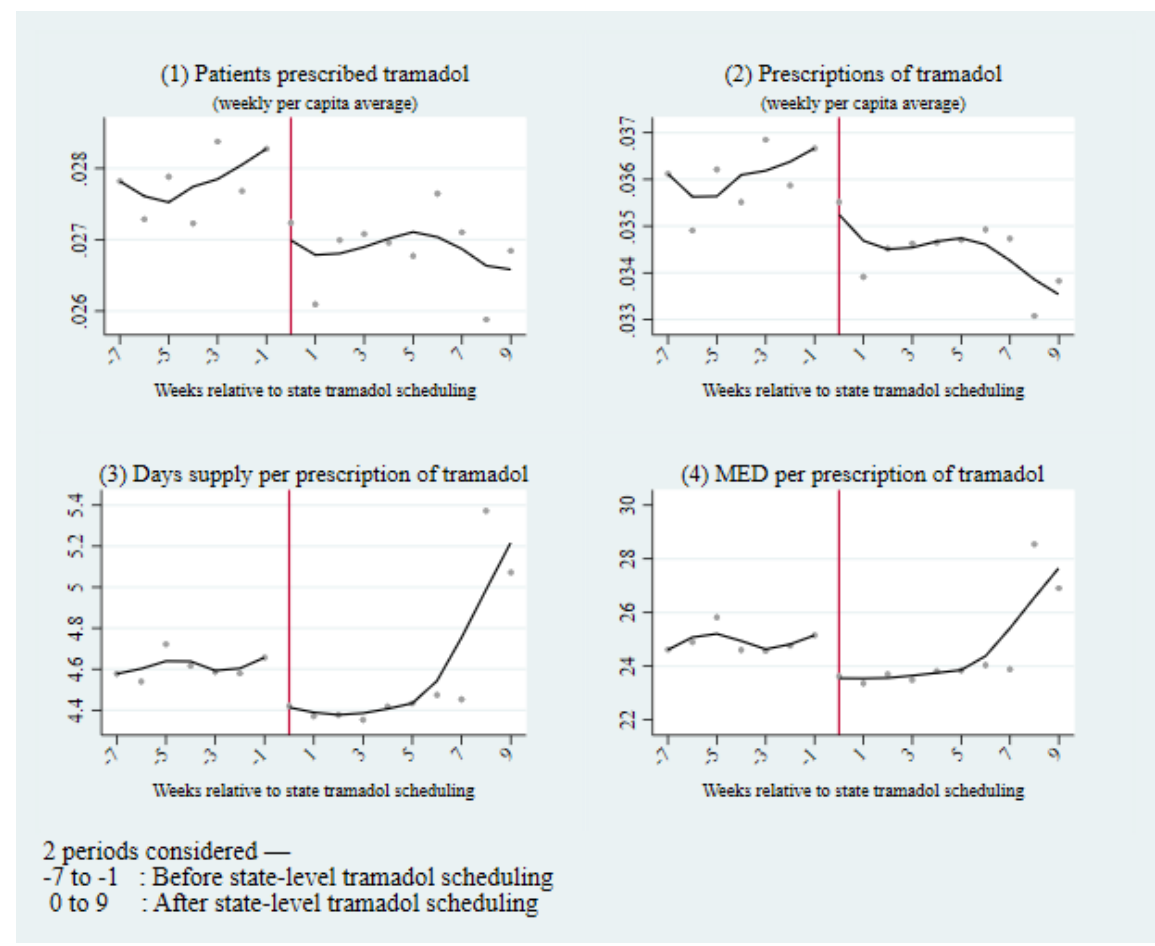

Notes: Authors' calculations based on Optum's de-identified Clinformatics ${ }^{\circledR}$ Data Mart system, a comprehensive commercial and Medicare Advantage claims database. Unit of observation is prescriber-week. Includes only the 9 states states - Illinois, Kentucky, Mississippi, New Mexico, North Dakota, Oklahoma, Tennessee, Wyoming and Georgia - that scheduled tramadol as a control substance at the state-level prior to federal law. Panel is centered at the timing of the state-level tramadol scheduling, depicted with the vertical line. This figure plots the prescription dispensing of tramadol. Four prescription dispensing outcomes are considered - user rates (1), prescription rates (2), average days' supply per Prescription (in Days) (3) and average Strength per Prescription (in MED) (4). The number of total patients in the database changes throughout our study period. The data do not report the number of patients enrolled with each prescriber in every week. Therefore, rates of patients prescribed (1) and prescriptions (2) are calculated with a denominator of the total number of unique patients the prescriber prescribed (any opioid or non-opioid drug) to each week. 
We next build on this descriptive analysis by describing our estimation strategy for identifying the impact of stricter controlled substance regulation on HCPs and tramadol on their prescribing.

\section{Methods}

In line with the non-parametric analysis presented in Figure 2, we use a local linear regression to evaluate the impact of HCPs and tramadol scheduling changes by comparing prescribing of the affected drugs adjacent to the cut-point. The unit of analysis is the prescriber-year-week. This is equivalent to estimating impacts on a subset of the data within a chosen bandwidth $h$ to the left and right of the cut-point, using the following regression model:

$$
Y_{s t}=\alpha+\beta_{0} T+\beta_{1} t_{s}+\epsilon_{s t}
$$

where $\alpha$ is the average value of the prescribing outcome following the scheduling changes; $Y_{s t}$ is the prescribing rate by prescriber $s$ in week $t ; T$ is an indicator for the period following the (up)scheduling and $t_{s}$ is a vector of indicator variables equal to 1 in the year-week specified. The coefficient $\beta_{0}$, for treatment assignment represents the marginal impact of the (up)scheduling at the cut-point.

We also examined if the new scheduling changes affected initial prescribing or if they affected subsequent refills, reflecting the new prohibition on HCPs refills and additional limitations on authorized refills of tramadol. To the extent that initial prescriptions are affected, that might reflect informational effects, whereas refills are also affected by the mandate nature of the regulations. In our data, we are able to identify each dispensed prescription as initial or a refill, and Model 11 was separately re-estimated for the sample of initial prescriptions and refills.

A concern in regression discontinuity $(\mathrm{RD})$ design is whether individuals can sort across the threshold, i.e., into or out of treatment, which would bias the empirical estimates (Hausman and Rapson, 2018). Usually, this can be tested indirectly and controlled for in three possible ways. First, we can examine whether there is any discontinuity in the density of 
the treatment assignment variable at the cut-point (McCrary, 2008). In our case treatment assignment is fully determined by the timing of the scheduling regulations, and the density of time is uniform, thus this test becomes irrelevant.

Another concern regarding RD designs is whether there are any discontinuities in other opioid related regulatory changes at the time of the (up)scheduling of HCPs and tramadol that, in theory, should not be affected by the scheduling changes. Enactment of other opioid related policies near the timing of the scheduling changes could be evidence of some states being more motivated to curb the over-prescribing of opioids and introducing other polices to achieve this goal. Inability to control for these potential covariates could bias our estimates. In Figure B1, we examine the prevalence of five state-level policy changes that have been associated with changes in opioid use - ACA expansion (Saloner et al., 2018), mandatory PDMPs (Buchmueller and Carey, 2018b; Meinhofer, 2018), pain clinic regulations (Dowell et al., 2016b), medical marijuana laws (Bradford et al., 2018) and day limit laws (Sacks et al., 2019; Davis et al., 2019a). From Figure B1, Panel A we note that there were no other opioid related regulatory changes surrounding the federal up-scheduling of HCPs. Considering the opioid policy environment surrounding the federal initial scheduling of tramadol, from Figure B1, Panel B we note that one of 38 states in our treatment sample, New Hampshire, underwent the ACA expansion just 4 weeks prior to tramadol's federal scheduling. To avoid confounding effects, New Hampshire, is omitted from the treatment sample for the evaluation of the effect of tramadol's federal initial scheduling on its prescribing. Finally, concurrent regulations that influence opioid prescribing may affect our estimates. To investigate this possibility, in a sensitivity test, we check for the robustness of our estimates to inclusion of other opioid related policies in Model 1 .

As another sensitivity test we also estimate an extended specification that allows the slope and the intercept to differ on either sides of the cut point as follows:

$$
Y_{s t}=\alpha+\beta_{0} T+\beta_{1} t_{s}+\beta_{2} T t_{s}+\epsilon_{s t}
$$

where the coefficient on the interaction term $t_{s}$ captures the change in slope of prescribing 
outcomes following (up-)scheduling. The remaining variables and model specifications are identical to Model11. Although the trend-break specification in Model2 2 has the advantage of allowing a level as well as a trend treatment effect, it increases the complexity of the model and reduces the power of the analysis. Therefore, if our treatment estimate from Model 1 is comparable to the point estimates from the more complex Model 1 , the simpler model with the same trend in prescribing before and after the scheduling change is our preferred specification.

Non-parametric analysis also revealed possible substitution from HCPs towards tramadol after the former was up-scheduled. Consequently, for the local linear regression discontinuity estimation of the impact of federal (up)scheduling we could consider maximal bandwidths of seven weeks before and after HCP and tramadol up-scheduling. The usual tradeoff between precision and bias holds; using all seven weeks of data would provide more precise estimates but results may be biased farther from the exact time of scheduling discontinuity. The optimal bandwidth can be determined using cross validation or equivalent 'plug-in' methods (Hahn and der Klaauw, 2001) that minimize the mean square prediction error. These methods, however, are computationally demanding, particularly when the number of observations is large, as is the case for our data. As an alternative, we estimate local linear regressions for alternative choices of bandwidths of 3-7 weeks to test whether the estimated effect is sensitive to the choice of bandwidth. We estimated the effect of state-level (up)scheduling of tramadol using a prescriber-week panel of the 9 states that scheduled tramadol prior to its federal scheduling, centered at the timing of the state-level tramadol scheduling. To get estimates of the effect of state-level level scheduling of tramadol that are directly comparable to the average treatment effect of the federal regulations, we first use an RD design identical to the federal evaluation. We also use a more standard estimation strategy for state policy variation, a difference-in-difference style (DD) event study that exploited the variation in timing of scheduling across the nine treated states. Model specification for the sensitivity test is detailed in Appendix C. 


\section{Results}

\subsection{Impact of federal scheduling changes}

Appendix Figure B2 plots the local linear regression discontinuity treatment estimates (Model 1) with the ninety five percent confidence intervals for alternative bandwidths. From Appendix Figure B2, we note that the federal (up)scheduling of HCPs (panel (a)) and tramadol (panel (b)) are associated with statistically significant declines in the rate of prescriptions and patients prescribed, as well as, average days' of supply and MED per prescription for the possible range of bandwidths. We also note, for both HCPs and tramadol, that the effect sizes are very similar for all alternative bandwidths.

To illustrate effect sizes, Tables 2 and 3 presents the estimates from the local linear regression discontinuity analysis for an arbitrarily selected bandwidth of five weeks before and five weeks after HCP and tramadol scheduling, respectively. The tables presents three different sets of estimates of the effect of federal (up-)scheduling on the prescription dispensing of the effected drug itself. Panel A presents the baseline local linear regression estimate from Model 1. Panel B presents the estimated treatment effect from the extended trend-break specification from Model 2 that allows both level and trend changes in prescription dispensing in

response to the federal (up-)scheduling changes. Finally, Panel C presents point estimates from our baseline specification that includes controls for other opioid related policies. 
From Table 2, we note that federal HCP up-scheduling is associated with a 10-13 percent decline in patients prescribed HCPs and HCP prescriptions dispensed and 8 percent decline in average days' of supply and MED per HCP prescription (Panel A). As expected, prescribing declines were more concentrated in refills (days supply of refills fell by 71 percent), possibly reflecting the new prohibition on HCP refills as a CII controlled substance. In comparison, days supply of initial Rx only fell by 6 percent.These estimates capture well the change in prescription dispensing due to the federal HCP up-scheduling and results do not change much if we allow for an additional change in trend response (Panel B). Finally, our treatment estimates do not appear to be driven by other opioid related policies in effect during this time, as Panel $\mathrm{C}$ shows that the effects are not substantially affected by their inclusion. In the federal policy case, there is in fact no reason to expect that inclusion of these additional policies would shift our point estimates at all as there is no similar discontinuity in these policies at the exact time of HCP federal up-scheduling (noted in Figure 3).

From Table 3, Panel A we note that the federal initial scheduling of tramadol as a schedule IV controlled substance is associated with more modest prescribing declines. Tramadol prescribing declines by 5-7 percent at the extensive margin - patients prescribed and prescriptions written - and by 2-3 percent at the intensive margin - average days' of supply and MED per tramadol prescription. Reductions in both initial prescriptions (27 percent decline) and permitted tramadol refills (48 percent decline) contributed to this decline. Again, our treatment estimates are robust to alternative model specification (Panel B) and inclusion of controls for other opioid related policies (Panel C). 
Table 2: Regression discontinuity: Effect of federal up-scheduling of HCPs on prescription dispensing of HCPs.

\begin{tabular}{|c|c|c|c|c|}
\hline & Patients & $\mathrm{Rx}$ & Days/Rx & $\mathrm{MED} / \mathrm{Rx}$ \\
\hline \multicolumn{5}{|c|}{ Panel A. Baseline local linear regression } \\
\hline Estimate & $\begin{array}{l}-0.01007^{* * *} \\
(0.0007)\end{array}$ & $\begin{array}{c}-0.01538^{* * *} \\
(0.0008)\end{array}$ & $\begin{array}{c}-0.7194^{* * *} \\
(0.0584)\end{array}$ & $\begin{array}{c}-5.1220^{* * *} \\
(0.4789)\end{array}$ \\
\hline \multicolumn{5}{|c|}{ Panel B. with additional trend-break treatment effect } \\
\hline Estimate & $\begin{array}{l}-0.01164^{* * *} \\
(0.0007)\end{array}$ & $\begin{array}{c}-0.01693^{* * *} \\
(0.0008)\end{array}$ & $\begin{array}{c}-0.7860 * * * \\
(0.0595)\end{array}$ & $\begin{array}{c}-5.6065^{* * *} \\
(0.4877)\end{array}$ \\
\hline \multicolumn{5}{|c|}{ Panel C. Baseline local linear regression with controls for other opioid related policies } \\
\hline Estimate & $\begin{array}{l}-0.01002^{* * *} \\
(0.0007)\end{array}$ & $\begin{array}{c}-0.01531^{* * *} \\
(0.0008)\end{array}$ & $\begin{array}{c}-0.7145^{* * *} \\
(0.0584)\end{array}$ & $\begin{array}{c}-5.0346^{* * * *} \\
(0.4778)\end{array}$ \\
\hline Dep. variable mean & 0.1000 & 0.1200 & 8.6300 & 64.220 \\
\hline Dep. variable SD & $(0.14125)$ & $(0.1595)$ & $(11.8033)$ & $(96.5538)$ \\
\hline $\mathrm{N}$ & 677,338 & 677,338 & 677,338 & 677,338 \\
\hline
\end{tabular}

Notes: Authors' calculations based on Optum's de-identified Clinformatics ${ }^{\circledR}$ Data Mart system, a comprehensive commercial and Medicare Advantage claims database. Unit of observation is prescriber-week. Observation window is June 2014 to October 2014. Unit of observation is prescriber-year-week. Eight tramadol prescription dispensing outcomes are considered - user rates for all prescriptions dispensed (1), prescription rates for all prescriptions dispensed (2), average days' supply per prescription (in Days) for all prescriptions dispensed (3), average strength per prescription (in MED) for all prescriptions dispensed (4), average days' supply per initial prescription (5), average days' supply per refill prescription (6), days' supply for all initial prescriptions (7), and days' supply for all refill prescriptions (8). The number of total patients in the database changes throughout our study period. The data do not report the number of patients enrolled with each prescriber in every week. Therefore, rates of patients prescribed (1) and prescriptions (2) are calculated with a denominator of the total number of unique patients the prescriber prescribed (any opioid or non-opioid drug) to each week. Panel A presents estimation results from baseline Model 1 Panel B presents estimation results from the extended Model 2 that allows the slope of the prescription dispensing to also vary on either side of the discontinuity. Panel $\mathrm{C}$ presents estimation results from baseline Model 1 with additional controls for other opioid related policies in effect in the prescriber's state in the given year-week. ${ }^{*} \mathrm{p}<0.05,{ }^{* *} \mathrm{p}<0.01,{ }^{* * *} \mathrm{p}<0.001$. 
Table 3: Regression discontinuity: Effect of federal initial scheduling of tramadol on prescription dispensing of tramadol.

\begin{tabular}{|c|c|c|c|c|c|c|c|c|}
\hline & Patients & $\mathrm{Rx}$ & Days/Rx & $\mathrm{MED} / \mathrm{Rx}$ & Days(Initial) & Days(Refill) & Days/Rx(Initial) & Days/Rx(Refill) \\
\hline \multicolumn{9}{|c|}{ Panel A. Baseline local linear regression } \\
\hline Estimate & $\begin{array}{l}-0.002179^{* * *} \\
(0.0004)\end{array}$ & $\begin{array}{c}-0.001885^{* * *} \\
(0.0004)\end{array}$ & $\begin{array}{c}-0.1177^{* *} \\
(0.0593)\end{array}$ & $\begin{array}{c}-0.8943^{* *} \\
(0.3708)\end{array}$ & $\begin{array}{c}1.2616^{* * *} \\
(0.0761)\end{array}$ & $\begin{array}{l}-1.4931^{* * *} \\
(0.0501)\end{array}$ & $\begin{array}{c}0.9000^{* * *} \\
(0.0523)\end{array}$ & $\begin{array}{c}-1.2189 * * * \\
(0.0388)\end{array}$ \\
\hline \multicolumn{9}{|c|}{ Panel B. with additional trend-break treatment effect } \\
\hline Estimate & $\begin{array}{l}-0.002678^{* * *} \\
(0.0004)\end{array}$ & $\begin{array}{c}-0.002476^{* * *} \\
(0.0004)\end{array}$ & $\begin{array}{c}-0.2049^{* * *} \\
(0.0604)\end{array}$ & $\begin{array}{c}-1.3666^{* * *} \\
(0.3771)\end{array}$ & $\begin{array}{c}1.2604^{* * *} \\
(0.0774)\end{array}$ & $\begin{array}{l}-1.6303^{* * *} \\
(0.0509)\end{array}$ & $\begin{array}{c}0.8984^{* * *} \\
(0.0533)\end{array}$ & $\begin{array}{c}-1.3261^{* * *} \\
(0.0396)\end{array}$ \\
\hline \multicolumn{9}{|c|}{ Panel C. Baseline local linear regression with controls for other opioid related policies } \\
\hline Estimate & $\begin{array}{l}-0.002135^{* * *} \\
(0.0004)\end{array}$ & $\begin{array}{c}-0.001832^{* * *} \\
(0.0004)\end{array}$ & $\begin{array}{c}-0.1102^{*} \\
(0.0593)\end{array}$ & $\begin{array}{c}-0.8553^{* * *} \\
(0.3703)\end{array}$ & $\begin{array}{c}1.2729 * * * \\
(0.0759)\end{array}$ & $\begin{array}{l}-1.4885^{* * *} \\
(0.0500)\end{array}$ & $\begin{array}{c}0.9062^{* * *} \\
(0.0523)\end{array}$ & $\begin{array}{c}-1.2157^{* * *} \\
(0.0389)\end{array}$ \\
\hline Dep. variable mean & .0314009 & .0400771 & 5.771567 & 30.68678 & 4.595367 & 3.106079 & 3.773882 & 2.616283 \\
\hline Dep. variable SD & $(0.0801318)$ & $(0.0915527)$ & $(12.32353)$ & $(77.30613)$ & $(14.61966)$ & $(11.95018)$ & $(10.36288)$ & $(9.017157)$ \\
\hline $\mathrm{N}$ & 696,784 & 696,784 & 696,784 & 696,784 & 696,784 & 696,784 & 696,784 & 696,784 \\
\hline
\end{tabular}

Notes: Authors' calculations based on Optum's de-identified Clinformatics ${ }^{\circledR}$ Data Mart system, a comprehensive commercial and Medicare Advantage claims database. Unit of observation is prescriber-week. Observation window is June 2014 to October 2014. Unit of observation is prescriber-year-week. Eight tramadol prescription dispensing outcomes are considered - user rates for all prescriptions dispensed (1), prescription rates for all prescriptions dispensed (2), average days' supply per prescription (in Days) for all prescriptions dispensed (3), average strength per prescription (in MED) for all prescriptions dispensed (4), average days' supply per initial prescription (5), average days' supply per refill prescription (6), days' supply for all initial prescriptions (7), and days' supply for all refill prescriptions (8). The number of total patients in the database changes throughout our study period. The data do not report the number of patients enrolled with each prescriber in every week. Therefore, rates of patients prescribed (1) and prescriptions (2) are calculated with a denominator of the total number of unique patients the prescriber prescribed (any opioid or non-opioid drug) to each week. Panel A presents estimation results from baseline Model 1. Panel B presents estimation results from the extended Model 2 that allows the slope of the prescription dispensing to also vary on either side of the discontinuity. Panel C presents estimation results from baseline Model 1 with additional controls for other opioid related policies in effect in the prescriber's state in the given year-week. ${ }^{*} \mathrm{p}<0.05,{ }^{* *} \mathrm{p}<0.01,{ }^{* * *} \mathrm{p}<0.001$ 


\subsection{Substitution to other prescription opioids}

Following the descriptive evidence of spill-over effects of scheduling changes on the prescription dispensing of other prescription opioids noted above, we formally estimate changes in the prescription dispensing of other opioids following the federal (up-)scheduling of HCPs and tramadol. Prescribers may respond to the new HCP regulation by switching patients to less restrictive CIV opioids, including the next most popular US opioid, tramadol, which now involve relatively less hassle cost to prescribe. Alternatively, prescribers may now perceive the risk of HCP use to their patients as equivalent to that from using more potent CII opioids like oxycodone. Being equally 'costly' to prescribe, prescribers may even switch their patients from HCPs to the more potent substitutes. Table 4 presents estimated changes in the prescription dispensing of tramadol (Panel A), other CIII-IV opioids (Panel B) and other CII opioids (Panel C), in response to the federal up-scheduling of HCPs. We find that both the rates of users and prescriptions of tramadol and other schedule IV opioids increased (by $\approx 12$ percent and $\approx 65$ percent, respectively) as a result of HCPs' federal up-scheduling. Despite the large magnitude increase in prescribing of other CIII-IV opioids their share in total opioid prescribing remained small. Prescribing of tramadol also increased at the intensive margin - 5 percent more days' of supply and higher MED per prescription of tramadol were authorized - but increases at the intensive margin were more modest. Additionally, as the prescription dispensing of HCPs reduced, the rate of users and prescriptions of other CII opioids increased by 7 percent and 3 percent, respectively. Average length of authorized CII opioid prescriptions also increased slightly by 2 percent. These analyses with HCPs' policy provides evidence that drug scheduling changes may have unintended consequences on related drugs, which must be taken into account for optimal policy formulation.

The case of tramadol policy spillovers is a little more complicated than for HCPs' policy change. For the short seven week period after the federal scheduling of tramadol as a CIV controlled substance and before the federal up-scheduling of HCPs, prescription dispensing of tramadol and HCPs were subject to similar controls. Table 5 presents changes in the 
prescription dispensing of HCPs and other CIV opioids following tramadol's federal initial scheduling. Unlike evidence of substitution from HCPs to other opioids following its tighter regulation, we find little evidence of substitution from tramadol towards other opioids. In fact, from Table 5 Panel A, we note that if anything, the rates of users of HCPs slightly decreased following tramadol's scheduling (1 percent decline), possibly reflecting the fact that, despite its scheduling, tramadol prescribing remained relatively less restrictive than the prescribing of other more tightly controlled opioids. But, the small decline in HCP users was at least partly compensated by a 2 percent increase in average days' of supply and MED per prescription of HCPs that WERE dispensed. In light of evidence suggesting substitution towards the other opioids, we examine next the net change in the total (MED) quantity of opioids dispensed, following the (up)scheduling of HCPs and tramadol. 
Table 4: Regression discontinuity: Effect of federal up-scheduling of HCPs on prescription dispensing of other opioids.

\begin{tabular}{|c|c|c|c|c|c|c|c|c|}
\hline & Patients & $\mathrm{Rx}$ & Days/Rx & $\mathrm{MED} / \mathrm{Rx}$ & Days(Initial) & Days(Refill) & Days/Rx(Initial) & Days/Rx(Refill) \\
\hline \multicolumn{9}{|l|}{ Panel A. Tramadol } \\
\hline Estimate & $\begin{array}{r}0.00465^{* * *} \\
(0.0004)\end{array}$ & $\begin{array}{c}0.00404^{* * *} \\
(0.0005)\end{array}$ & $\begin{array}{c}0.2865 * * * \\
(0.0603)\end{array}$ & $\begin{array}{c}1.3828^{* * *} \\
(0.371)\end{array}$ & $\begin{array}{c}0.4664^{* * *} \\
(0.081)\end{array}$ & $\begin{array}{c}-0.1242^{* * *} \\
(0.0473)\end{array}$ & $\begin{array}{c}0.3136^{* * *} \\
(0.0548)\end{array}$ & $\begin{array}{c}-0.05415 \\
(0.0372)\end{array}$ \\
\hline Dep. variable mean & 0.03026 & 0.03867 & 5.62567 & 29.81785 & 5.524353 & 1.941012 & 4.412845 & 1.695663 \\
\hline Dep. variable SD & $(0.0787)$ & $(0.0901552)$ & $(12.0826)$ & $(73.9788)$ & $(16.4943)$ & $(8.8489)$ & $(11.0837)$ & $(7.0846)$ \\
\hline \multicolumn{9}{|c|}{ Panel B. Other CIII-CIV opioids } \\
\hline Estimate & $\begin{array}{r}0.004935^{* * *} * \\
(0.0003)\end{array}$ & $\begin{array}{c}0.005637^{* * *} \\
(0.0004)\end{array}$ & $\begin{array}{c}0.2145^{* * *} \\
(0.0317)\end{array}$ & $\begin{array}{c}4.8698^{* * *} \\
(1.7961)\end{array}$ & $\begin{array}{c}0.3272^{* * *} \\
(0.0455)\end{array}$ & $\begin{array}{c}-0.008631 \\
(0.0191)\end{array}$ & $\begin{array}{c}0.2200^{* * *} \\
(0.0285)\end{array}$ & $\begin{array}{c}-0.05805 \\
(0.0409)\end{array}$ \\
\hline Dep. variable mean & 0.01000 & 0.02000 & 1.5500 & 26.850 & 1.5100 & 0.4100 & 1.2400 & 2.0700 \\
\hline Dep. variable SD & $(0.06000)$ & $(0.07000)$ & $(6.2700)$ & $(356.46)$ & $(8.4300)$ & $(3.7600)$ & $(5.6200)$ & $(7.8400)$ \\
\hline \multicolumn{9}{|c|}{ Panel C. Other C2 opioids } \\
\hline \multirow[t]{2}{*}{ Estimate } & $0.004480^{* * *}$ & $0.002365^{* *}$ & $0.1269^{* *}$ & -0.7237 & $\mathrm{n} / \mathrm{a}$ & $\mathrm{n} / \mathrm{a}$ & $\mathrm{n} / \mathrm{a}$ & $\mathrm{n} / \mathrm{a}$ \\
\hline & $(0.0006)$ & $(0.0009)$ & $(0.0561)$ & $(8.4712)$ & $\mathrm{n} / \mathrm{a}$ & $\mathrm{n} / \mathrm{a}$ & $\mathrm{n} / \mathrm{a}$ & $\mathrm{n} / \mathrm{a}$ \\
\hline Dep. variable mean & 0.05733 & 0.08891 & 6.40819 & 367.8313 & $\mathrm{n} / \mathrm{a}$ & $\mathrm{n} / \mathrm{a}$ & $\mathrm{n} / \mathrm{a}$ & $\mathrm{n} / \mathrm{a}$ \\
\hline Dep. variable SD & $(0.12593)$ & $(0.18548)$ & $(11.26661)$ & $(1695.506)$ & $\mathrm{n} / \mathrm{a}$ & $\mathrm{n} / \mathrm{a}$ & $\mathrm{n} / \mathrm{a}$ & $\mathrm{n} / \mathrm{a}$ \\
\hline $\mathrm{N}$ & 677,338 & 677,338 & 677,338 & 677,338 & 677,338 & 677,338 & 677,338 & 677,338 \\
\hline
\end{tabular}

Notes: Authors' calculations based on Optum's de-identified Clinformatics ${ }^{\circledR}$ Data Mart system, a comprehensive commercial and Medicare Advantage claims database. Unit of observation is prescriber-week. Observation window is August 2014 to November 2014. Unit of observation is prescriber-year-week. Eight HCP prescription dispensing outcomes are considered - user rates for all prescriptions dispensed (1), prescription rates for all prescriptions dispensed (2), average days' supply per prescription (in Days) for all prescriptions dispensed (3), average strength per prescription (in MED) for all prescriptions dispensed (4), average days' supply per initial prescription (5), average days' supply per refill prescription (6), days' supply for all initial prescriptions (7), and days' supply for all refill prescriptions (8). The number of total patients in the database changes throughout our study period. The data do not report the number of patients enrolled with each prescriber in every week. Therefore, rates of patients prescribed (1) and prescriptions (2) are calculated with a denominator of the total number of unique patients the prescriber prescribed (any opioid or non-opioid drug) to each week. Baseline Model 1 estimates of change in prescription dispen $\mathrm{p}<0.01, * * * \mathrm{p}<0.001$. 
Table 5: Regression discontinuity: Effect of federal initial scheduling of tramadol on prescription dispensing of other opioids.

\begin{tabular}{|c|c|c|c|c|c|c|c|c|}
\hline & Patients & $\mathrm{Rx}$ & Days/Rx & $\mathrm{MED} / \mathrm{Rx}$ & Days(Initial) & Days(Refill) & Days/Rx(Initial) & Days/Rx(Refill) \\
\hline \multicolumn{9}{|c|}{ Panel A. Hydrocodone } \\
\hline Estimate & $\begin{array}{r}-0.001250^{*} \\
(0.0007)\end{array}$ & $\begin{array}{c}0.000006 \\
(0.0008)\end{array}$ & $\begin{array}{c}0.1651^{* * *} \\
(0.057)\end{array}$ & $\begin{array}{c}1.2107^{* * *} \\
(0.4657)\end{array}$ & $\begin{array}{c}-0.01474 \\
(0.147)\end{array}$ & $\begin{array}{l}0.1636^{*} \\
(0.0856)\end{array}$ & $\begin{array}{c}0.09734^{*} \\
(0.0535)\end{array}$ & $\begin{array}{c}0.1170^{* * *} \\
(0.0413)\end{array}$ \\
\hline Dep. variable mean & 0.0991863 & 0.1267131 & 8.452351 & 62.73915 & 10.88847 & 4.223858 & 6.896451 & 2.874367 \\
\hline Dep. variable SD & $(0.1445665)$ & $(0.163525)$ & $(11.57943)$ & $(94.51519)$ & $(30.24867)$ & $(17.27352)$ & $(10.84808)$ & $(8.383091)$ \\
\hline \multicolumn{9}{|c|}{ Panel B. All other CIII-CIV opioids } \\
\hline Estimate & $\begin{array}{r}-0.000203 \\
(0.0003)\end{array}$ & $\begin{array}{c}-0.000105 \\
(0.0003)\end{array}$ & $\begin{array}{l}0.01029 \\
(0.0293)\end{array}$ & $\begin{array}{c}0.2569 \\
(1.7058)\end{array}$ & $\begin{array}{l}0.02947 \\
(0.0399)\end{array}$ & $\begin{array}{c}-0.01140 \\
(0.0178)\end{array}$ & $\begin{array}{l}0.01936 \\
(0.0261)\end{array}$ & $\begin{array}{c}-0.01394 \\
(0.0152)\end{array}$ \\
\hline Dep. variable mean & 0.01000 & 0.02000 & 1.3500 & 25.150 & 1.3000 & 0.3700 & 1.0600 & 0.3500 \\
\hline Dep. variable SD & 0.06000 & $(0.07000)$ & $(5.8500)$ & $(347.93)$ & $(8.00)$ & $(3.5600)$ & $(5.2100)$ & $(3.0400)$ \\
\hline $\mathrm{N}$ & 696,784 & 696,784 & 696,784 & 696,784 & 696,784 & 696,784 & 696,784 & 696,784 \\
\hline
\end{tabular}

Notes: Authors' calculations based on Optum's de-identified Clinformatics ${ }^{\circledR}$ Data Mart system, a comprehensive commercial and Medicare Advantage claims database. Unit of observation is prescriber-year-week. Observation window is June 2014 to October 2014. Unit of observation is prescriber-year-week. Eight tramadol prescription dispensing outcomes are considered - user rates for all prescriptions dispensed (1), prescription rates for all prescriptions dispensed (2), average days' supply per prescription (in Days) for all prescriptions dispensed (3), average strength per prescription (in MED) for all prescriptions dispensed (4), average days' supply per initial prescription (5), average days' supply per refill prescription (6), days' supply for all initial prescriptions (7), and days' supply for all refill prescriptions (8). The number of total patients in the database changes throughout our study period. The data do not report the number of patients enrolled with each prescriber in every week. Therefore, rates of patients prescribed (1) and prescriptions (2) are calculated with a denominator of the total number of unique patients the prescriber prescribed (any opioid or non-opioid drug) to each week. Baseline Model 1 estimates of change in prescription dispensing of HCPs (Panel A) and other CIV opioids (Panel B) in response to the federal initial scheduling of tramadol. ${ }^{*} \mathrm{p}<0.05,{ }^{* *} \mathrm{p}<0.01,{ }_{* * *} \mathrm{p}<0.001$. 
Table 6 presents the regression discontinuity estimates of the effect of up-scheduling of HCPs (Panel A) and the initial scheduling of tramadol (Panel B) on the total (MED) quantity dispensed of each specific opioid (class) - HCPs, tramadol, other CIII-IV and other CII opioids - and the aggregate prescription dispensing across all opioids. From Panel A we note that federal up-scheduling of HCPs led to a 12 percent decline in total MED quantity of dispensed HCPs. However, the decline in the prescription dispensing of HCPs was compensated by a 4 percent increase in total MED of dispensed tramadol. Overall, the total MED quantity of all opioids dispensed declined by 1 percent following HCPs' policy, and the decline is not statistically significant at conventional levels of significance.

In Panel B, we note that the total MED of tramadol dispensed declined by 4 percent following the federal initial scheduling of tramadol. In line with evidence from Table 5 , tramadol's policy did not significantly impact the prescription dispensing of other opioids individually. But, altogether, the small magnitude increases in prescription dispensing of more potent substitutes (HCPs and other CII opioids) following tramadol's scheduling washed out the decline in total MED quantity of dispensed tramadol, leaving the total MED quantity of all opioids dispensed unchanged, statistically speaking. It is noteworthy, that seven weeks later when HCPs were federally up-scheduled, the 4 percent decline in total MED of tramadol dispensed that resulted from its scheduling was completely undone by a 4 percent increase in its total MED dispensed (Panel A). Therefore, as noted earlier (discussion of Figure 2p, if we were to abstract away from the interim seven week window between the federal initial scheduling of tramadol and up-scheduling of HCPs, it would appear as if tramadol's scheduling had no impact on its prescribing, and tramadol prescribing consistently increased throughout.

Appendix Figure E1 shows long term trends in total MED of 5 different drug classes HCPs, other CII opioids, tramadol, other CIII-CIV opioids and the aggregate of all opioids - in Optum between 2007-2018. The vertical dashed line represents the timing of federal HCP up-scheduling. We note a plateauing off of HCP prescribing starting in 2013 after a steady increase throughout 2007-2012, and a steep decline in prescribing following its federal 
up-scheduling (green dotted line). Total MED prescribed of other CII opioids continues to gradually decline throughout 2013-2014, and then begins to creep up again before declining sharply in 2017 (blue dashed line). Total MED of prescribed tramadol steadily increased though out 2007-2016, with only a very slight dip in 2014q3 when it was initially federally scheduled as a controlled substance, followed again by a slow and steady increase after HCPs' up-scheduling. The increase in prescribing of other less controlled opioids is even more apparent right after the up-scheduling of HCPs (black dashed-dotted line). Overall, the federal up-scheduling of HCPs does not have a large visible impact on the aggregate MED prescribed across all prescription opioids (solid black line), which continues along its pre-upscheduling slight downward trend, followed by an increase in 2015q1. This descriptive evidence reiterates that HCP up-scheduling does not appear to have led to a substantive decline in the aggregate MED prescribed of all opioids in the longer run as well.

To ensure that our finding of competitive spillover effect of federal HCP up-scheduling on aggregate opioid prescribing is not simply an artifact of claims in the private sector (Optum), we also examined changes in aggregate opioid prescribing in two additional samples (1) transactional ARCOS data and (2) Medicaid State Drug Utilization Data. The ARCOS data are available at the transaction level for the years 2006-2014. In the public use version of ARCOS, the total mmes are provided only quarterly, not weekly, and only at a very aggregate level, combining both retail community pharmacies (which are affected by CSA) and hospitals and other institutions (which are not). The CSA only covers the retail community pharmacies. We observe in our detailed ARCOS data (at the weekly level, and separates transactions by type of outlet) that only one fifth of the total HCP MMEs per week during our study period is distributed through retail community pharmacies, which suggests that there is high value added in using the transactional version for our study. However there is a large drawback: tramadol is not tracked in ARCOS, thus we cannot study the effects of its rescheduling nor the spillover from HCP rescheduling. We nevertheless can study the own policy effect of HCP rescheduling and possible spillovers of it to other CII-C1V drugs tracked in ARCOS. We obtained a county-week panel of total MME supplied of 4 drug classes 
between 2011-2014 - HCPs (1), CIII-CIV tracked in ARCOS (select codeine products and buprenorphine products for pain) (2), other CII opioids excluding HCPs (3) and all opioids (4).7 As in our Optum results, in Figure E2, raw trends in ARCOS retail supply of the 4 drug classes shows a steep decline in HCP supply following its up-scheduling (vertical red dashed line), increase in retail supply of select CIII-CIV opioids starting slightly prior to the the federal up-scheduling of HCP and continuing several weeks after (panel 2) and no significant change in MME supplied of other CII opioids (panel 3). Overall, there appears to be a slight shift down in aggregate supply of all opioids right after HCP up-scheduling but this decline appears small in magnitude and not sustained.

Table E1 presents regression discontinuity estimates of the effect of federal HCP upscheduling on MME of opioids supplied as recorded in the transactional ARCOS data. To facilitate comparison, we again consider the 14-week period surrounding the federal upscheduling of HCPs (2014w34-2014w48). From results presented in Table E1 we note a large shift down in the aggregate supply of HCP for retail purposes following the drugs upscheduling. The decline in HCP supply is accompanied by an significant upward trend in supply of the less controlled CIII-CIV opioids like codeine products and buprenorphine for pain (column 2). HCP up-scheduling does not have a significant impact on the supply of other CII opioids. Finally, although the aggregate supply of all opioids for retail purposes declines after the federal up-scheduling of HCPs, this decline is again not statistically significant at any conventional levels.

In Figure E3 we present long term trends in prescribing of 4 opioid classes - HCPs, tramadol, other CII opioids and all opioids between 2011-2018 for the Medicaid State Drug Utilization Data (SDUD) ${ }^{8}$. From Figure E3 it appears that for the SDUD sample HCP prescribing increased prior to its federal up-scheduling and then returned to its pre-increase level following its up-scheduling. Moreover, there appears to no impact of HCP up-scheduling on the prescribing of other opioid classes and the overall prescription of all opioids remains

\footnotetext{
${ }^{7}$ We are extremely grateful to David Bradford for providing us these data.

${ }^{8}$ The SDUD do not record the length of the prescription and for purposes of analysis each prescription is approximated to be 14 days long
} 
unchanged. Regression discontinuity estimates in Table E2 find no statistically significant effect of federal HCP up-scheduling on any of the drug classes considered in the SDUD sample.

This analysis reveals that the tighter CSA controls on HCPs and tramadol were effective in reducing the prescription dispensing of the affected drugs. However, the declines in the prescription dispensing of HCPs and tramadol were completely offset by increased prescription dispensing of other less regulated or equally regulated (but more potent) opioids, resulting in no net change in dispensed total MED quantity of all opioids (as noted earlier in Figure 3. In this sense, the federal scheduling changes did not have their intended effect. 
Table 6: Regression discontinuity: Effect of federal up-scheduling of HCPs and initial scheduling of tramadol on total MED of opioids dispensed.

\begin{tabular}{|c|c|c|c|c|c|c|c|}
\hline & \multicolumn{7}{|c|}{ Total MED } \\
\hline & hydrocodone & tramadol & Other CIII-CIV opioids & Other CII opioids & All CIII-CIV & All CII & All opioids \\
\hline \multicolumn{8}{|c|}{ Panel A. Impact hydrocodone federal upscheduling } \\
\hline Estimate & $\begin{array}{r}-1.1806^{* * *} \\
(0.1201)\end{array}$ & $\begin{array}{c}0.1986^{* * *} \\
(0.0629)\end{array}$ & $\begin{array}{c}0.6375^{* *} \\
(0.2970)\end{array}$ & $\begin{array}{c}0.7643 \\
(2.4255)\end{array}$ & $\begin{array}{c}0.8360^{* * *} \\
(0.3043)\end{array}$ & $\begin{array}{l}-0.4163 \\
(2.4449)\end{array}$ & $\begin{array}{c}0.4197 \\
(2.4741)\end{array}$ \\
\hline Dep. variable mean & 11.680 & 3.8600 & 3.4200 & 90.670 & 7.2800 & 102.35 & 109.63 \\
\hline Dep. variable SD & $(24.490)$ & $(12.540)$ & $(59.260)$ & $(488.16)$ & $(60.670)$ & $(491.86)$ & $(497.27)$ \\
\hline $\mathrm{N}$ & 677,338 & 677,338 & 677,338 & 677,338 & 677,338 & 677,338 & 677,338 \\
\hline \multicolumn{8}{|c|}{ Panel B. Impact tramadol federal initial scheduling } \\
\hline Estimate & $\begin{array}{r}0.07102 \\
(0.1205)\end{array}$ & $\begin{array}{c}-0.1859^{* * *} \\
(0.0630)\end{array}$ & $\begin{array}{l}0.02749 \\
(0.2728)\end{array}$ & $\begin{array}{c}2.0998 \\
(2.3775)\end{array}$ & $\begin{array}{l}-0.1584 \\
(0.2805)\end{array}$ & $\begin{array}{c}2.1708 \\
(2.3960)\end{array}$ & $\begin{array}{l}2.0124 \\
(2.4212)\end{array}$ \\
\hline Dep. variable mean & 11.650 & 4.0300 & 3.0100 & 87.810 & 7.0400 & 99.460 & 106.50 \\
\hline Dep. variable SD & $(24.720)$ & $(13.380)$ & $(51.470)$ & $(484.06)$ & $(53.310)$ & $(487.92)$ & $(492.62)$ \\
\hline $\mathrm{N}$ & 696,784 & 696,784 & 696,784 & 696,784 & 696,784 & 696,784 & 696,784 \\
\hline
\end{tabular}

Notes: Authors' calculations based on Optum's de-identified Clinformatics ${ }^{\circledR}$ Data Mart system, a comprehensive commercial and Medicare Advantage claims database. Unit of observation is prescriber-year-week. Observation window is August 2014 to November 2014 (Panel A) and June 2014 to October 2014 (Panel B). Presented coefficients are regression discontinuity estimates from baseline Model 1 of the effect of the federal up-scheduling of HCPs (Panel A) and the federal initial scheduling of tramadol (Panel B) on the total (MED) quantity dispensed of each specific opioid (class) - HCPs, tramadol, other CIV opioids, other CII opioids, and the aggregate prescription dispensing across all opioids. ${ }^{*}$ $\mathrm{p}<0.05, * * \mathrm{p}<0.01, * * * \mathrm{p}<0.001$. 


\subsection{Impact of state-level scheduling changes}

We investigate the effect of tighter state-level scheduling changes on prescribing in the nine states that scheduled tramadol prior to its federal scheduling, using the local-linear regression Model $1 y^{9}$ Centering the prescriber-year-week panel at the timing of state-level tramadol scheduling, the effectiveness of the controlled substance designation of tramadol at the state level is evaluated by comparing prescribing of tramadol in the five weeks prior to with its prescribing in the five weeks after state regulations.

Estimated coefficients of the impact of state-level tramadol initial scheduling on its' prescribing are presented in Table 7. Similar to the federal CSA case, we present estimates from the baseline specification (Panel A), extended specification that allows level and trend treatment effects (Panel B) and baseline specification with controls for other opioid related policies (Panel C). From Table 7 we note that state tramadol scheduling is associated with $\approx 5$ percent decline in all tramadol prescribing outcomes (Panel A). Similar to the federal effect, due to the new limits on refills, prescribing declines were larger for refills than for intial prescriptions - days' of supply of refills fell by 20 percent, whereas days' of supply of initial prescriptions fell by 10 percent. Our results do not change if we allow for an additional change in trend response (Panel B). Finally, the treatment estimates are also not sensitive to the inclusion of controls for other opioid related policies in effect during this time (Panel C).

Our treatment group consists of 9 states that designated tramadol as a controlled substance at the state-level at different dates between 2007-2013, before its federal scheduling. Usually in such situations, a typical approach would be a difference-in-difference (DD) event study, exploiting the variation in timing of scheduling across states. The DD event study has two advantages over our regression discontinuity approach. First, the DD event study would utilize prescribing data from both the treated and non-treated states to estimate the change in tramadol prescribing in states that regulated tramadol relative to states that did

\footnotetext{
${ }^{9}$ There was a singular instance of state-level up-scheduling of HCPs. New York up-scheduled HCPs to schedule II on February 23, 2013, prior to its federal scheduling. However, New York concurrently scheduled tramadol as a CIV controlled substance,and, therefore, we cannot distinguish between the two effects.
} 
not. Second, the DD event study would allow us to examine longer-term dynamic response of prescription dispensing to tramadol's controlled substance designation. Keeping these advantages in mind we estimated the effect of state-level level scheduling of tramadol using a standard difference-in-difference (DD) event study (refer Appendix C for details).

Results from Table C1 broadly confirm our regression discontinuity treatment effect estimates - prescribing of tramadol significantly declined following its state CSA scheduling. Again, rates of users and prescriptions (extensive margin) declined more $(\approx 17 \%$ decline) than the average days' of supply and MED per prescription $(\approx 11 \%$ decline at the intensive margin) following its scheduling. Compared to the RD estimates the larger DD effect sizes are to be expected since the DD analysis considers a much longer post-treatment period and effects may build over time as previously authorized refills run out. Estimated effects are also robust to inclusion of controls for other opioid-related policies (and prescriber fixed effects; details in Appendix C). Comparing the magnitude of the effect sizes, the estimated declines in opioid prescribing from the DD regression are twice those calculated using our regression discontinuity specification, possibly reflecting larger cumulative effects of the scheduling changes in the long-run.

Despite the advantages of using a DD event study approach, we cannot use a similar approach to evaluate the impact of the federal tramadol scheduling since the regulation concurrently impacted all states ${ }^{10}$ Moreover, the estimated average treatment effect from the DD evaluation of the state regulations is not directly comparable with regression discontinuity based average treatment effect of the federal regulations. Therefore, behavioral responses to federal and state scheduling regulations are compared using the regression discontinuity based average treatment effects of the state and federal controlled substance designation of tramadol. Our estimates indicate that federal and state-level schedulings were almost equally effective in reducing the prescribing of the affected drugs. This may be because a

\footnotetext{
${ }^{10}$ Even the states that had previously (up)scheduled HCPs and tramadol at their individual state-levels may be impacted by the federal scheduling regulation and would therefore not serve as an appropriate control group. Appendix Figure D1 show that states that had previously (up)scheduled tramadol and states that had not were both affected by the (up)scheduling changes at the federal level.
} 
drug's controlled substance status is enforced similarly at the point of dispensation (e.g. direct pharmacy inability to refill) irrespective of whether the (up)scheduling was at the federal or state level. In this sense, CSA policy changes are distinct from most other instances of federal versus states regulation, such as the Affordable Care Act young adult laws, where federal policy has been noted to have a larger impact. In terms of policy implications, our results suggest that states can effectively implement CSA scheduling changes at the state-level to better control the prescribing of substances with high incidence of misuse. 
Table 7: Regression discontinuity: Effect of state-level initial scheduling of tramadol on prescription dispensing of tramadol.

\begin{tabular}{|c|c|c|c|c|c|c|c|c|}
\hline & Patients & $\mathrm{Rx}$ & Days/Rx & $\mathrm{MED} / \mathrm{Rx}$ & Days(Initial) & Days(Refill) & Days/Rx(Initial) & Days/Rx(Refill) \\
\hline \multicolumn{9}{|c|}{ Panel A. Baseline local linear regression } \\
\hline \multicolumn{9}{|c|}{ Panel $\boldsymbol{B}$. with additional trend-break treatment effect } \\
\hline Estimate & $\begin{array}{c}-0.001479^{* *} \\
(0.0007)\end{array}$ & $\begin{array}{c}-0.001758^{* *} \\
(0.0008)\end{array}$ & $\begin{array}{c}-0.1901^{*} \\
(0.0974)\end{array}$ & $\begin{array}{c}-1.1317^{*} \\
(0.6228)\end{array}$ & $\begin{array}{c}0.3634^{* * *} \\
(0.0992)\end{array}$ & $\begin{array}{c}-0.5543^{* * *} \\
(0.0848)\end{array}$ & $\begin{array}{c}0.3357^{* * *} \\
(0.081)\end{array}$ & $\begin{array}{c}-0.4964^{* * *} \\
(-0.0692)\end{array}$ \\
\hline \multicolumn{9}{|c|}{ Panel C. Baseline local linear regression with controls for other opioid related policies } \\
\hline Dep. variable mean & 0.02789 & 0.036226 & 4.632285 & 24.98299 & 3.203784 & 2.549688 & 2.815435 & 2.233721 \\
\hline Dep. variable SD & $(0.07749)$ & $(0.08884)$ & (11.02984) & $(70.7774)$ & $(10.7154)$ & (10.1805) & $(8.8615)$ & $(8.2719)$ \\
\hline $\mathrm{N}$ & 209,133 & 209,133 & 209,133 & 209,133 & 209,133 & 209,133 & 209,133 & 209,133 \\
\hline
\end{tabular}

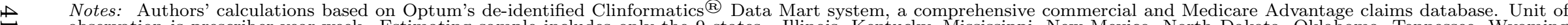
observation is prescriber-year-week. Estimating sample includes only the 9 states - Illinois, Kentucky, Mississippi, New Mexico, North Dakota, Oklahoma, Tennessee, Wyoming tramadol prescription dispensing outcomes are considered - user rates for all prescriptions dispensed (1), prescription rates for all prescriptions dispensed (2), average days' supply per prescription (in Days) for all prescriptions dispensed (3), average strength per prescription (in MED) for all prescriptions dispensed (4), average days' supply per initial prescription (5), average days' supply per refill prescription (6), days' supply for all initial prescriptions (7), and days' supply for all refill prescriptions (8). The number of total patients in the database changes throughout our study period. The data do not report the number of patients enrolled with each prescriber in every week Therefore, rates of patients prescribed (1) and prescriptions (2) are calculated with a denominator of the total number of unique patients the prescriber prescribed (any opioid or non-opioid drug) to each week. Panel A (1) and pros a each week. Panel A presents estimation results from baseline Model 1 . Panel B presents estimation results from the extended Model 2 that allows the slope of the prescription dispensing to also vary state in the given year-week. ${ }^{*} \mathrm{p}<0.05,{ }^{* *} \mathrm{p}<0.01,{ }^{* * *} \mathrm{p}<0.001$. 


\section{Sensitivity Analyses}

\subsection{Heterogeneity by baseline prescribing}

In the same vein with prior work (Beheshti, 2019), our conceptual discussion highlighted the heterogeneity of response that may depend on baseline rates of tramadol and HCP prescribing ${ }^{11}$ We thus next examine if the prescribing changes in response to the federal upscheduling of HCPs and control substance designation of tramadol differs by prescriber-level heterogeneity in HCP and tramadol prescribing volumes at baseline in the newly federally treated states. High volume HCP and tramadol prescribers may be more impacted by the scheduling changes, or they may feel that their familiarity with the drug means they are less influenced by the new policy in terms of the risks they perceive in prescribing the medication, thus it is ambiguous whether we should expect their prescribing to respond the most. To test for heterogeneous treatment effects, we sort prescribers into quartiles based on their prescribing of the affected drug in the 15 months (April 2013-July 2014) prior to the federal scheduling changes. We re-estimate Model 1 using these stratified samples. Results in Table 8 and 9 compare prescribing changes for the bottom quartile of baseline HCP and tramadol prescribers (Panel A) to that for the top quartile of baseline HCP and tramadol prescribers (Panel B).

The estimating sample for these secondary analyses is a balanced panel of the federally treated states - 49 states for HCPs and 37 states for tramadol. The observations windows capture prescribing between July 13, 2014-September 20, 2014 for tramadol and August 31, 2014- November 8, 2014 for HCPs. Table 8 presents changes in total MED quantity prescribed of HCPs, tramadol, other CIV opioids, other CII opioids and aggregate of all opioids by the bottom and top quartile of high volume HCP prescribers at baseline, following HCP federal up-scheduling. First, we note that the decline in HCP prescribing was concentrated in the baseline high volume HCP prescribers (Panel A). Second, following HCPs' federal

\footnotetext{
${ }^{11}$ Beheshti $(2019)$ shows a clear drop in the amount of hydrocodone distributed in the zip3s with higher pre-existing levels of hydrocodone consumption following the federal up-scheduling of HCPs.
} 
scheduling, prescribers who were previously prescribing high volumes of HCPs increased their prescribing of tramadol (and other CIV and CII opioids, but these are statistically insignificant), whose prescribing was generally less restricted than HCPs.

Similarly, for high and low baseline volume tramadol prescribers, Table 9, presents changes in prescribing of tramadol, HCPs, other schedule IV opioids, other schedule II opioids and the aggregate of all opioids in response to tramadol's initial CSA federal scheduling. Again, tramadol prescribing falls more sharply for the high volume prescribers, and in fact even increases for the low volume prescribers. However, unlike HCPs, we find no evidence of substitution from tramadol to HCPs or other CIV opioids following the federal scheduling of tramadol. 
Table 8: Effects of Federal HCP Rescheduling on HCP prescribing: Heterogeneity by provider baseline prescribing volume.

\begin{tabular}{|c|c|c|c|c|c|c|c|}
\hline \multicolumn{8}{|c|}{ Total MED } \\
\hline & hydrocodone & tramadol & Other CIII-CIV opioids & Other $\mathrm{C} 2$ opioids & All CIII-CIV & All CII & All opioids \\
\hline \multicolumn{8}{|c|}{ Panel A. Bottom 25 percent baseline hydrocodone prescribers } \\
\hline \multirow[t]{2}{*}{ Estimate } & -0.06046 & -0.07940 & -0.008180 & 12.199 & -0.08758 & 12.138 & 12.051 \\
\hline & $(0.2064)$ & $(0.2542)$ & $(0.9048)$ & $(9.2433)$ & $(0.9377)$ & $(9.2421)$ & $(9.2731)$ \\
\hline Dep. variable mean & 3.4300 & 5.5000 & 2.8400 & 101.74 & 8.3500 & 105.17 & 113.52 \\
\hline Dep. variable S.D. & 12.830 & $(17.410)$ & $(63.850)$ & $(633.28)$ & $(65.960)$ & $(633.05)$ & $(635.33)$ \\
\hline $\mathrm{N}$ & 73,741 & 73,741 & 73,741 & 73,741 & 73,741 & 73,741 & 73,741 \\
\hline \multicolumn{8}{|c|}{ Panel B. Top 25 percent baseline hydrocodone prescribers } \\
\hline Estimate & $\begin{array}{r}-1.9193^{* * *} \\
(0.2237)\end{array}$ & $\begin{array}{c}0.2905^{* * *} \\
(0.0941)\end{array}$ & $\begin{array}{c}1.4805^{* * *} \\
(0.5077)\end{array}$ & $\begin{array}{c}0.3945 \\
(4.0039)\end{array}$ & $\begin{array}{c}1.7710^{* * *} \\
(0.5182)\end{array}$ & $\begin{array}{l}-1.5248 \\
(4.0460)\end{array}$ & $\begin{array}{c}0.2463 \\
(4.1025)\end{array}$ \\
\hline Dep. variable mean & 19.480 & 4.3900 & 4.9000 & 127.96 & 9.2800 & 147.44 & 156.72 \\
\hline Dep. variable S.D. & 31.660 & 12.970 & 69.380 & 557.30 & 70.760 & 562.86 & 570.03 \\
\hline $\mathrm{N}$ & 329,775 & 329,775 & 329,775 & 329,775 & 329,775 & 329,775 & 329,775 \\
\hline
\end{tabular}

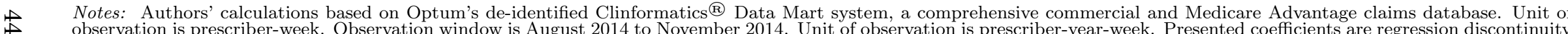
observation is prescriber-week. Observation window is August 2014 to November 2014. Unit of observation is prescriber-year-week. Presented coefficients are regression discontinuity estimates from baseline Model 1 of the effect of federal up-scheduling of HCPs on the total (MED) quantity dispensed of each specific opioid (class) - HCPs, tramadol, other CIV opioids, other CII opioids, and the aggregate prescription dispensing across all opioids. We used total MED quantity of HCPs prescribed during of April 2013-July 2014 to identify low volume prescribers (bottom quartile) and high volume prescribers (top quartile). Standard errors in parentheses.* $\mathrm{p}<0.05, * * \mathrm{p}<0.01,{ }^{*} * * \mathrm{p}<0.001$. 
Table 9: Effects of Federal initial scheduling of Tramadol on Tramadol Prescribing: Heterogeneity by provider baseline prescribing volume.

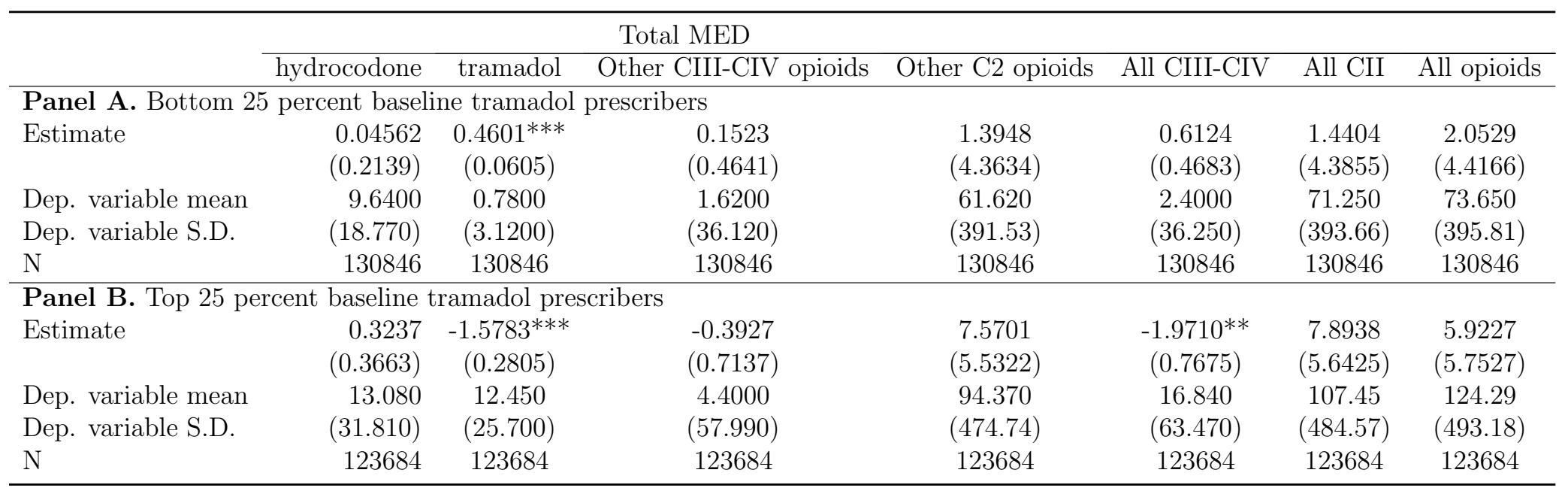

Notes: Authors' calculations based on Optum's de-identified Clinformatics ${ }^{\circledR}$ Data Mart system, a comprehensive commercial and Medicare Advantage claims database. Unit of observation is prescriber-year-week. Observation window is June 2014 to October 2014. Presented coefficients are regression discontinuity estimates from baseline Model 1 of the effect of initial federal scheduling of tramadol on the total (MED) quantity dispensed of each specific opioid (class) - HCPs, tramadol, other CIV opioids, other CII opioids, and the aggregate prescription dispensing across all opioids. We used total MED quantity of tramadol prescribed during of April 2013-July 2014 to identify low volume prescribers (bottom quartile) and high volume prescribers (top quartile). Standard errors in parentheses.* $\mathrm{p}<0.05,{ }^{* *} \mathrm{p}<0.01,{ }^{* * *} \mathrm{p}<0.001$. 


\subsection{Heterogeneity by prescriber specialty}

Another dimension of heterogeneous response to scheduling changes may be along the lines of prescriber specialty. Opioid use for acute care, for instance post-surgery, is considered clinically appropriate. In this case, we expect tighter CSA controls on HCPs and tramadol to have lesser impact on the prescribing of these drugs by surgeons than other specialists for whom opioid prescribing may be clinically confirmed therefore would respond to the negative information signals and transactions costs of prescribing. We explore heterogeneous responses to the scheduling changes of HCPs and tramadol by re-estimating Model 1 within stratified samples of prescribers in seven different specialties - primary care, registered nurses/physician assistants/nurse practitioners, pain management, surgery, hematology, neurology and other physicians.

Table 10, presents changes in total MED quantity of HCPs (Panel A) and tramadol (Panel B) prescribed, by specialty, following their federal (up)scheduling. In Table 10 we note heterogeneous impacts of federal HCP and tramadol (up)scheduling by prescriber specialty. At baseline, pain specialists prescribe the highest total MED quantity of HCPs per week, 2.5 times that of the next highest prescribers, primary care givers. After HCPs were federally up-scheduled, the total MED quantity of HCPs declined for most specialties except pain specialists, neurologists and hematologists. It could be that pain specialists are the providers for whom the information in the rescheduling is least novel thus does not change their behavior, or it could be that they see the most severe cases and thus the transactional costs are not as important as clinical benefits of retaining the same therapy; future work should examine whether there are changes in the types of patients for whom the affected drugs are continued vs. patients who are switched to other medications. The largest decline in total MED quantity of HCPs prescribed was for registered nurses/physician assistants/nurse practitioners prescribers (15 percent), followed by primary care and surgeons (13 percent). After the federal controlled substance designation of tramadol total MED quantity of tramadol prescribed declined significantly only for registered nurses/physician assistants/nurse prac- 
titioners, who could no longer prescribe tramadol as a controlled substance in some states (scope of practice laws). 
Table 10: Regression discontinuity: Effect of federal up-scheduling of HCPs and initial scheduling of tramadol on prescription dispensing of HCPs and tramadol by prescriber specialty.

\begin{tabular}{|c|c|c|c|c|c|c|c|}
\hline & Primary & $\mathrm{RN} / \mathrm{NP} / \mathrm{SA} / \mathrm{PA}$ & Pain & Surgery & Hematology & Neurology & Other physician \\
\hline \multicolumn{8}{|c|}{ Panel A. Total MED of HCPs } \\
\hline Estimate & $\begin{array}{c}-20.516^{* * *} \\
(2.2797)\end{array}$ & $\begin{array}{c}-14.549^{* * *} \\
(2.9569)\end{array}$ & $\begin{array}{c}-11.425 \\
(47.4851)\end{array}$ & $\begin{array}{c}-5.4315^{* * *} \\
(1.9621)\end{array}$ & $\begin{array}{l}-5.5365 \\
(4.2145)\end{array}$ & $\begin{array}{c}-14.811 \\
(10.9235)\end{array}$ & $\begin{array}{c}-7.0870^{*} \\
(4.1402)\end{array}$ \\
\hline Dep. variable mean & 157.675 & 94.34 & 404.70 & 42.61 & 57.89 & 130.59 & 90.486 \\
\hline Dep. variable S.D. & $(319.57)$ & $(234.09)$ & $(1006.82)$ & $(98.33)$ & $(109.30)$ & $(254.31)$ & $(420.23)$ \\
\hline $\mathrm{N}$ & 294932 & 89254 & 7780 & 39080 & 11141 & 8565 & 170358 \\
\hline \multicolumn{8}{|c|}{ Panel B. Total MED of tramadol } \\
\hline Estimate & $\begin{array}{c}-1.547 \\
(1.0207)\end{array}$ & $\begin{array}{c}-4.7952^{* * *} \\
(1.1986)\end{array}$ & $\begin{array}{l}-7.4183 \\
(8.2331)\end{array}$ & $\begin{array}{c}-0.2228073 \\
(0.76649)\end{array}$ & $\begin{array}{c}0.7671 \\
(1.6823)\end{array}$ & $\begin{array}{r}4.1465 \\
(5.8488)\end{array}$ & $\begin{array}{c}-2.0498^{*} \\
(1.0938)\end{array}$ \\
\hline Dep. variable mean & 65.26138 & 35.73639 & 62.0554 & 7.790335 & 8.834928 & 52.08554 & 20.05068 \\
\hline Dep. variable S.D. & $(139.3044)$ & $(93.44927)$ & $(177.4929)$ & $(39.93038)$ & $(37.55955)$ & $(142.04)$ & $(115.3392)$ \\
\hline $\mathrm{N}$ & 302178 & 93217 & 174129 & 7717 & 11321 & 8905 & 40141 \\
\hline
\end{tabular}

Notes: Authors' calculations based on Optum's de-identified Clinformatics ${ }^{\circledR}$ Data Mart system, a comprehensive commercial and Medicare Advantage claims database. Observation window is August 2014 to November 2014 (Panel A) and June 2014 to October 2014 (Panel B). Unit of observation is prescriber-year-week. Presented coefficients are regression discontinuity estimates of the effect of up-scheduling of HCPs (Panel A) and initial scheduling of tramadol (Panel B) on the total (MED) quantity prescription dispensed of HCPs and tramadol, respectively, from baseline Model 1. by prescriber specialty. Prescribing changes in response to the scheduling changes are considered for seven different specialties primary care, registered nurses/physician assistants/nurse practitioners, pain management, surgery, hematology, neurology and other physicians. Standard errors in parentheses.* $\mathrm{p}<0.05, * * \mathrm{p}<0.01, * * * \mathrm{p}<0.001$ 


\section{Discussion and conclusion}

In response to well established evidence of the opioid epidemic facing the US, state and federal policies have attempted to control opioid prescribing through several channels. While PDMPs and other state restrictions on prescribers have been often studied, there is less evidence on another route to restricting opioid prescription supply, through the DEA CSA. In 2014, two very large-market-share products experienced a sudden stricter regulation, enabling us to answer several questions new to the literature. The results in this study consider the impact of CSA regulations in scheduling and up-scheduling, on own and competitor market shares, and how federal and state versions of the same laws compare in their effects on opioid prescribing. Using claims data from a large, commercially insured population, this study finds that prescribing of HCPs, tramadol and other opioid analgesics significantly changed in response to the DEA designating tramadol as a controlled substance for the first time in July 2014 and moving HCPs to a more restrictive CSA tier in October 2014. We find evidence that (up-)scheduling of HCPs and tramadol were associated with significant declines in the prescribing of both opiates. However, the decline in tramadol prescribing was not sustained. After an initial decline in prescribing after its control substance designation, tramadol prescribing again began to significantly increase immediately following the upscheduling of HCPs, when it became a less 'costly' substitute to HCPs.

Stricter CSA regulations could reduce prescribing of HCPs and tramadol by raising the marginal cost of prescribing. For instance, due to restrictions on refills that will require more frequent office visits and mandatory PDMP reviews prior to any prescribing. The higher marginal cost of prescribing a more tightly controlled substance would only impact the extensive margin of prescribing - rates of prescriptions and patients prescribed - but, not increase with the authorized days' supply or dosage per prescription. CSA (up)scheduling may also increase the prescriber's perception of the risk associated with the use of the affected drug and result in reduced prescribing at both the extensive as well as intensive margin.

We find that following federal- and state- level scheduling changes, prescribing declined at 
both the extensive margin of prescribing, i.e. lowered the rates of prescriptions and patients prescribed and at the intensive margin - average days' supply and MED per prescription. The decrease in prescribing of the effected drug at the intensive margin suggests that stricter CSA scheduling changes provide valuable negative information and salience about the associated risks from use, in addition to the simple regulation. Moreover, federal and state-level scheduling scheduling changes appear equally effective in reducing prescribing of the effected drug by sending a clear signal of the higher abuse liability of the drugs than was previously known.

Another important insight from our results is that scheduling changes not only impact the prescribing of the affected drugs, but also have significant spillover effects on the prescribing of less regulated or 'costly' substitutes, which must be taken into account for optimal policy formulation. Up-scheduling of HCPs lead to significant increase in the prescribing of tramadol and, to a lesser extent, increase in the prescribing of other CIV and CII opioids. Any evaluation of HCP up-scheduling that does not take into account the unintended substitution from HCPs towards the other opioids would overestimate the effect of HCP regulation in limiting opioid prescribing. Our results reveal that the substantial decline in prescribing of HCPs and tramadol following their CSA (up)scheduling was completely offset by a compensatory increase in the prescribing of related drugs. In this sense, the regulations were not effective in reducing the total prescription dispensing of all opioids.

Overall, the regulations did not result in a decline in the aggregate prescription dispensing of all opioids. Our findings imply that the Controlled Substance Act (CSA) scheduling of drugs can serve as an important policy tool to curb high levels of opioid prescribing. However, the efficacy of CSA scheduling is undermined in the presence of substitutes. 


\section{References}

Ali, M. M., Dowd, W. N., Classen, T., Mutter, R., and Novak, S. P. (2017). Prescription drug monitoring programs, nonmedical use of prescription drugs, and heroin use: Evidence from the national survey of drug use and health. Addictive behaviors, 69:65-77.

Alpert, A., Dykstra, S., and Jacobson, M. (2020). How do prescription drug monitoring programs reduce opioid prescribing? the role of hassle costs versus information. Technical report, National Bureau of Economic Research.

Alpert, A., Powell, D., and Pacula, R. L. (2018). Supply-side drug policy in the presence of substitutes: Evidence from the introduction of abuse-deterrent opioids. American Economic Journal: Economic Policy, 10(4):1-35.

Babalonis, S., Lofwall, M., Nuzzo, P., Siegel, A., and Walsh, S. (2013). Abuse liability and reinforcing efficacy of oral tramadol in humans. Drug and Alcohol Dependence, 129:116124.

Bala, R., Bhardwaj, P., and Chintagunta, P. K. (2017). Pharmaceutical product recalls: Category effects and competitor response. Marketing Science, 36(6):931-943.

Bao, Y., Wen, K., Johnson, P., Jeng, P. J., Meisel, Z. F., and Schackman, B. R. (2018). Assessing the impact of state policies for prescription drug monitoring programs on highrisk opioid prescriptions. Health Affairs, 37(10):1596-1604.

Beheshti, D. (2019). The impact of opioids on the labor market: Evidence from drug rescheduling. Technical report, Working Paper.

Bernhardt, M., Taylor, R., Hagan, J., Patel, N., Chumpitazi, C., Fox, K., and C., G. (2016). Evaluation of opioid prescribing after rescheduling of hydrocodone-containing products. American Journal of Health-System Pharmacy, 74(24):2046-2053.

Bradford, A. C., Bradford, W. D., Abraham, A., and Adams, G. B. (2018). Association between us state medical cannabis laws and opioid prescribing in the medicare part $\mathrm{d}$ population. JAMA internal medicine, 178(5):667-672.

Buchmueller, T. C. and Carey, C. (2018a). The effect of prescription drug monitoring programs on opioid utilization in medicare. American Economic Journal: Economic Policy, 10(1):77-112.

Buchmueller, T. C. and Carey, C. (2018b). The effect of prescription drug monitoring programs on opioid utilization in medicare. American Economic Journal: Economic Policy, 10(1):77-112.

Bush, D. (2015). The cbhsq report: Emergency department visits for adverse reactions involving the pain medication tramadol. Substance Abuse and Mental Health Services Administration, Center for Behavioral Health Statistics and Quality. Rockville, MD.

Bütikofer, A., Cronin, C. J., and Skira, M. M. (2020). Employment effects of healthcare policy: Evidence from the 2007 fda black box warning on antidepressants. Journal of Health Economics, page 102348.

Cawley, J. and Rizzo, J. (2008). Spillover effects of prescription drug withdrawals. Advances in Health Economics and Health Services Research, 19:119-144.

CDC (2018). Multiple cause of death data on cdc wonder. department of health and human services. Atlanta, GA. http://wonder.cdc.gov/mcd.html.

Collins, M., K. S. and Tennyson, S. (2013). Drug withdrawals and the utilization of therapeutic substitutes: The case of vioxx. Journal of Economic Behavior Organization, 86(Feb):148-168. 
Davis, C. S., Lieberman, A. J., Hernandez-Delgado, H., and Suba, C. (2019a). Laws limiting the prescribing or dispensing of opioids for acute pain in the united states: A national systematic legal review. Drug and alcohol dependence, 194:166-172.

Davis, C. S., Lieberman, A. J., Hernandez-Delgado, H., and Suba, C. (2019b). Laws limiting the prescribing or dispensing of opioids for acute pain in the united states: A national systematic legal review. Drug and Alcohol Dependence, 194:166-172.

Daysal, N. M. and Orsini, C. (2015). Spillover effects of drug safety warnings on preventive health care use. The BE Journal of Economic Analysis \& Policy, 15(1):179-208.

DEA (2009). Automation of reports and consolidated orders system (arcos). https://www.deadiversion.usdoj.gov/arcos/index.html.

DEA (2018). Tramadol. diversion control division. drug and chemical evaluation section. Technical report.

DEA, 2014a. Schedules of controlled substances: Placement of tramadol into schedule iv. final rule.

DEA, 2014b. Schedules of controlled substances: Rescheduling of hydrocodone combination products from schedule iii to schedule ii. final rule.

Deiana, C. and Giua, L. (2018). The US Opidemic: Prescription Opioids, Labour Market Conditions and Crime. MPRA Paper, University Library of Munich, Germany.

Dowell, D., Haegerich, T., and Chou, R. (2016a). Cdc guideline for prescribing opioids for chronic pain - united states. $M M W R, 65(1): 1-49$.

Dowell, D., Zhang, K., Noonan, R. K., and Hockenberry, J. M. (2016b). Mandatory provider review and pain clinic laws reduce the amounts of opioids prescribed and overdose death rates. Health Affairs, 35(10):1876-1883.

Evans, W. N., Lieber, E., and Power, P. (2019). How the reformulation of oxycontin ignited the heroin epidemic. Review of Economics and Statistics, 101.

Fleming, M., Driver, L., Sansgiry, S., Abughosh, S., Wanat, M., Sawant, R., Ferries, E., Reeve, K., and Todd, K. (2017). Physicians' intention to prescribe hydrocodone combination products after rescheduling: A theory of reasoned action approach. Research in Social and Administrative Pharmacy, 13(3):503-512.

Freedman, S., K. M. . L. M. (2012). Product recalls, imperfect information, and spillover effects: Lessons from the consumer response to the 2007 toy recalls. The Review of Economics and Statistics, 94(2):371-388.

Grecu, A. M., Dave, D. M., and Saffer, H. (2019). Mandatory access prescription drug monitoring programs and prescription drug abuse. Journal of Policy Analysis and Management, 38(1):181-209.

Gudin, J. and Lee, A. (2013). The downside of upscheduling. Pain Medicine, 14(11):1628-1629 .

Hahn, J., P. T. and der Klaauw, W. V. (2001). Identification and estimation of treatment effects with a regression-discontinuity design. Econometrica, 69(1):201-209.

Hausman, C. and Rapson, D. (2018). Regression discontinuity in time: Considerations for empirical applications. Annual Review of Resource Economics, 10(1):533-552.

Hollingsworth, A., Ruhm, C. J., and Simon, K. (2017). Macroeconomic conditions and opioid abuse. Journal of Health Economics, 56:222-233.

IMS Health (2012). Top 25 medicines by dispensed prescriptions (u.s.). https: //www.imshealth.com/deployedfiles/imshealth/Global/Content/Corporate/ Press\%20Room/2012_U.S/Top_25_Medicines_Dispensed_Prescriptions_U.S. .pdf, 
note $="[$ Online; accessed 28-June-2019]".

IQVIA (2019). Medicine use and spending in the u.s. https://www.iqvia.com/insights/the-iqvia-institute/reports/ medicine-use-and-spending-in-the-us-a-review-of-2018-and-outlook-to-2023, note $=$ "[Online; accessed 28-June-2020]".

Jones, C., Lurie, P., and Throckmorton, D. (2016). Effect of us drug enforcement administration's rescheduling of hydrocodone combination analgesic products on opioid analgesic prescribing. JAMA Internal Medicine, 176(3).

Kaestner, R. and Ziedan, E. (2019). Mortality and socioeconomic consequences of prescription opioids: Evidence from state policies. Technical report, National Bureau of Economic Research.

Kaiser Family Foundation (2019). Status of state action on the medicaid expansion decision. Technical report.

Kilby, A. (2016). Opioids for the masses: welfare tradeoffs in the regulation of narcotic pain medications. In 2016 Fall Conference: The Role of Research in Making Government More Effective. APPAM.

Kuo, Y.-F., Raji, M. A., Liaw, V., Baillargeon, J., and Goodwin, J. S. (2018). Opioid prescriptions in older medicare beneficiaries after the 2014 federal rescheduling of hydrocodone products. Journal of the American Geriatrics Society, 66(5):945-953.

Mallatt, J. (2018). The effect of prescription drug monitoring programs on opioid prescriptions and heroin crime rates. Available at SSRN 3050692.

McCrary, J. (2008). Manipulation of the running variable in the regression discontinuity design: A density test. Journal of Econometrics, 142:698-714.

Meara, E., Horwitz, J. R., Powell, W., McClelland, L., Zhou, W., O’Malley, A. J., and Morden, N. E. (2016). State legal restrictions and prescription-opioid use among disabled adults. New England Journal of Medicine, 375(1):44-53.

Meinhofer, A. (2018). Prescription drug monitoring programs: The role of asymmetric information on drug availability and abuse. American Journal of Health Economics, 4(4):504526.

Miotto, K., Cho, A., Khalil, M., Blanco, K., Sasaki, J., and R, R. (2017). Trends in tramadol: Pharmacology, metabolism, and misuse. Anesth Analg, 124(1):44-51.

Murimi, I., Chang, H., Bicket, M., Jones, C., and Alexander, G. (2019). Using trajectory models to assess the effect of hydrocodone upscheduling among chronic hydrocodone users. Pharmacoepidemiol Drug Saf., 28(1):70-79.

Nguyen, T. D., Bradford, W. D., and Simon, K. I. (2019). How do opioid prescribing restrictions affect pharmaceutical promotion? lessons from the mandatory access prescription drug monitoring programs. Technical report, National Bureau of Economic Research.

Northrup, T., Carroll, K., Suchting, R., Villarreal, Y., Zare, M., and Stotts, A. (2019). The impact of increased hydrocodone regulation on opioid prescribing in an urban safety-net health care system. The Journal of the American Board of Family Medicine, 32 (3):362374.

Parkinson, K., Price, J., Simon, K. I., and Tennyson, S. (2014). The influence of fda advisory information and black box warnings on individual use of prescription antidepressants. Review of Economics of the Household, 12(4):771-790.

PDAPS (2018). Prescription drug abuse policy system. http://pdaps.org. Accessed: 2018-01-30. 
Popovici, I., Maclean, J. C., Hijazi, B., and Radakrishnan, S. (2018). The effect of state laws designed to prevent nonmedical prescription opioid use on overdose deaths and treatment. Health Economics, 27(2):294-305.

Report, T. D. (2013). Substance abuse and mental health services administration, center for behavioral health statistics and quality. Highlights of the 2011 Drug Abuse Warning Network (DAWN) Findings on Drug-Related Emergency Department Visits, February.

Romley, J. and Shih, T. (2017). Product safety spillovers and market viability for biologic drugs. International Journal of Health Economics and Management, 17(2):135-158.

Sacks, D. W., Hollingsworth, A., Nguyen, T. D., and Simon, K. I. (2019). Can policy affect initiation of addictive substance use? evidence from opioid prescribing. Technical report, National Bureau of Economic Research.

Saloner, B., Levin, J., Chang, H.-Y., Jones, C., and Alexander, G. C. (2018). Changes in buprenorphine-naloxone and opioid pain reliever prescriptions after the affordable care act medicaid expansion. JAMA network open, 1(4):e181588-e181588.

Tjaderborn, M., Jönsson, A., Ahlner, J., and Hägg, S. (2009). Tramadol dependence: a survey of spontaneously reported cases in sweden. Pharmacoepidemiol Drug Saf, 18:1192$-1198$.

Toledo, C. and Villas-Boas, S. B. (2019). Safe or not? consumer responses to recalls with traceability. Applied Economic Perspectives and Policy, 41(3):519-541.

UNITED STATES DISTRICT COURT NORTHERN DISTRICT OF OHIO EASTERN DIVISION. National prescription opiate litigation (case no. 1:17-md-2804).

Wen, H., Hockenberry, J. M., Jeng, P. J., and Bao, Y. (2019). Prescription Drug Monitoring Program Mandates: Impact On Opioid Prescribing And Related Hospital Use. Health Affairs, 38(9):1550-1556.

Zabihi, E., Hoseinzaadeh, A., Emami, M., Mardani, M., Mahmoud, B., and Akbar, M. (2011). Potential for tramadol abuse by patients visiting pharmacies in northern iran. Subst Abuse, 5:11-15.

Zacny, J. (2005). Profiling the subjective, psychomotor, and physiological effects of tramadol in recreational drug users. Drug and Alcohol Dependence, 80:273-278.

Zhang, H. and Liu, Z. (2013). The investigation of tramadol dependence with no history of substance abuse: a cross-sectional survey of spontaneously reported cases in guangzhou city, china. Biomed Research International, 283425.

Ziedan, E. and Kaestner, R. (2020). Effect of prescription opioids and prescription opioid control policies on infant health. Technical report, National Bureau of Economic Research. 


\section{A Effective dates of opioid related state policies}

Table A1: Effective dates of state-level scheduling of tramadol as a CSA Schedule IV controlled substance, prior to its federal scheduling in June 2014.

\begin{tabular}{|c|c|c|}
\hline State & Effective Date & Source \\
\hline Arkansas & March 3, 2007 & http://www.arkleg.state.ar.us/assembly/2007/R/Pages/BillInformation.aspx?measureno=HB2347 \\
\hline Georgia & April 29, 2014 & https://gdna.georgia.gov/blog/2014-05-02/tramadol-now-schedule-iv-controlled-substance-georgia \\
\hline Illinois & January 1,2012 & http://ilga.gov/legislation/ilcs/ilcs4.asp?DocName=072005700HArt\%2E+II\&ActID=1941\&ChapterID=53\&SeqStart $=600000 \&$ SeqEnd=2600000 \\
\hline Kentucky & December 5, 2008 & https://pharmacy.ky.gov/BoardInformation/2008\%20Board\%20Meetings/December\%2017\%202008.pdf \\
\hline Mississippi & July 1,2011 & https://www.mbp.ms.gov/Newsletters/July\%202011\%20Newsletter.pdf \\
\hline New Mexico & March 7, 2011 & http://wWw.rld.state.nm.us/uploads/files/Regulation\%2020\%20Controlled\%20Substance\%20Additions(1).pdf \\
\hline New York & February 23, 2013 & https://opwdd.ny.gov/opwdd_resources/information_for_clinicians/As_Part_of_the_I \\
\hline North Dakota & March 23, 2013 & https://www.legis.nd.gov/assembly/63-2013/session-laws/documents/foods.pdf \\
\hline Ohio† & September 1, 2014 & https://nabp.pharmacy/wp-content/uploads/2016/06/0H082014.pdf \\
\hline Oklahoma & November 1, 2012 & http://www.oklegislature.gov/cf_pdf/2011-12\%20ENR/hb/hb2942\%20enr.pdf \\
\hline Tennessee & April 7,2011 & https://www.tn.gov/content/dam/tn/health/documents/Tramadol.pdf \\
\hline Wyoming & July 1, 2011 & https://www.wyoleg.gov/Legislation/2011/HB0062 \\
\hline
\end{tabular}


Table A2: Implementation dates of other opioid related state policies.

\begin{tabular}{|c|c|c|c|c|c|}
\hline State & $\begin{array}{c}\text { Must Acces } \\
\text { Date }^{1}\end{array}$ & $\begin{array}{l}\text { Alternative } \\
\text { Date }^{1}\end{array}$ & Schedules Monitored $^{2}$ & $\begin{array}{c}\text { Delegate } \\
\text { Allowance } \\
\text { Date }^{3}\end{array}$ & $\begin{array}{l}\text { Day Limit } \\
\text { Date }^{3}\end{array}$ \\
\hline Alabama & & & II-V \& Drugs of Concern & $06 / 28 / 07$ & \\
\hline Alaska & $07 / 17 / 17$ & & II-IV only & $01 / 01 / 12$ & $07 / 26 / 17$ \\
\hline Arizona & $10 / 16 / 17$ & & II-V only & $12 / 01 / 08$ & \\
\hline Arkansas & $01 / 08 / 17$ & & II-V \& Drugs of Concern & $05 / 16 / 13$ & \\
\hline California & $04 / 02 / 18$ & & II-IV only & $2009-\mathrm{Q} 4$ & \\
\hline Colorado & & & II-V only & $02 / 04 / 08$ & \\
\hline Connecticut & $10 / 01 / 15$ & & II-V \& Drugs of Concern & & $07 / 01 / 16$ \\
\hline Delaware & $03 / 01 / 12$ & No must access & II-V \& Drugs of Concern & $08 / 21 / 12$ & $04 / 01 / 17$ \\
\hline District of Columbia & & & II-V \& Drugs of Concern & & \\
\hline Florida & & & II-V only & $10 / 17 / 11$ & \\
\hline Georgia & $07 / 13 / 14$ & & II-V only & $07 / 01 / 13$ & \\
\hline Hawaii & & & II-V \& Drugs of Concern & $1997-$ Q 1 & $07 / 01 / 16$ \\
\hline Idaho & & & II-V \& Drugs of Concern & 06/01/99 & \\
\hline Illinois & $01 / 01 / 18$ & & II-V \& Drugs of Concern & & $01 / 01 / 12$ \\
\hline Indiana & $07 / 01 / 14$ & & II-V \& Drugs of Concern & $2005-\mathrm{Q} 1$ & $07 / 01 / 17$ \\
\hline Iowa & & & II-IV only & $03 / 19 / 09$ & \\
\hline Kansas & & & II-IV \& Drugs of Concern & $04 / 01 / 11$ & \\
\hline Kentucky & $07 / 20 / 12$ & & II-V \& Drugs of Concern & $07 / 01 / 99$ & $06 / 29 / 17$ \\
\hline Louisiana & $07 / 01 / 12$ & No must access & II-V \& Drugs of Concern & $01 / 01 / 09$ & $08 / 01 / 17$ \\
\hline Maine & & & II-IV only & $01 / 01 / 05$ & $01 / 01 / 17$ \\
\hline Maryland & $07 / 01 / 18$ & & II-V only & $12 / 20 / 13$ & $05 / 25 / 17$ \\
\hline Massachusetts & $07 / 01 / 14$ & & II-V \& Drugs of Concern & $2011-\mathrm{Q} 1$ & $03 / 14 / 16$ \\
\hline Michigan & & & II-V only & $2003-\mathrm{Q} 1$ & \\
\hline Minnesota & $01 / 01 / 17$ & & II-V \& Drugs of Concern & $04 / 15 / 10$ & $07 / 01 / 17$ \\
\hline Mississippi & & & II-V \& Drugs of Concern & & Pre1989 \\
\hline Missouri & & & II-IV only & $2006-\mathrm{Q} 1$ & \\
\hline Montana & & & II-V only & $11 / 01 / 12$ & \\
\hline Nebraska & & & II-V \& Drugs of Concern & $04 / 14 / 11$ & \\
\hline Nevada & $10 / 01 / 07$ & $10 / 01 / 15$ & II-IV only & $07 / 01 / 97$ & $06 / 16 / 17$ \\
\hline New Hampshire & $01 / 21 / 16$ & & II-IV only & $10 / 16 / 14$ & $01 / 01 / 17$ \\
\hline New Jersey & $11 / 01 / 15$ & & II-V \& Drugs of Concern & $01 / 05 / 12$ & $05 / 16 / 17$ \\
\hline New Mexico & $09 / 28 / 12$ & & II-V only & $08 / 01 / 05$ & \\
\hline New York & $08 / 27 / 13$ & & II-V \& Drugs of Concern & $02 / 01 / 10$ & $07 / 22 / 16$ \\
\hline North Carolina & & & II- $\mathrm{V}$ only & $10 / 01 / 07$ & $01 / 01 / 18$ \\
\hline North Dakota & & & II-V \& Drugs of Concern & $09 / 01 / 07$ & \\
\hline Ohio & 03/01/12 & $12 / 31 / 15$ & II-V \& Drugs of Concern & $10 / 02 / 06$ & $08 / 31 / 17$ \\
\hline Oklahoma & $03 / 01 / 11$ & $11 / 01 / 15$ & II-V \& Drugs of Concern & $2006-\mathrm{Q} 3$ & \\
\hline Oregon & & & II-IV \& Drugs of Concern & $09 / 01 / 11$ & \\
\hline Pennsylvania & $01 / 01 / 17$ & & II-V only & & $01 / 03 / 17$ \\
\hline Rhode Island & $06 / 28 / 16$ & & II-IV only & $2012-\mathrm{Q} 3$ & $03 / 22 / 17$ \\
\hline South Carolina & $05 / 19 / 17$ & & II-IV only & $09 / 01 / 08$ & $06 / 13 / 07$ \\
\hline South Dakota & & & II-V only & $03 / 01 / 12$ & \\
\hline Tennessee & $07 / 01 / 13$ & & II-V \& Drugs of Concern & $01 / 01 / 07$ & $10 / 01 / 13$ \\
\hline Texas & 09/01/19 & & II-V only & $01 / 01 / 82$ & \\
\hline Utah & $05 / 09 / 17$ & & II-V \& Drugs of Concern & $01 / 01 / 97$ & $03 / 22 / 17$ \\
\hline Vermont & $11 / 15 / 13$ & & II-IV only & $04 / 01 / 09$ & $07 / 01 / 17$ \\
\hline Virginia & $07 / 01 / 15$ & $11 / 01 / 13$ & II-V \& Drugs of Concern & $06 / 01 / 06$ & $03 / 15 / 17$ \\
\hline Washington & & & II-V \& Drugs of Concern & $01 / 04 / 12$ & \\
\hline West Virginia & 06/08/12 & & II-V \& Drugs of Concern & $2005-\mathrm{Q} 1$ & \\
\hline Wisconsin & & & II-V \& Drugs of Concern & $06 / 01 / 13$ & \\
\hline Wyoming & & & II-V \& Drugs of Concern & $10 / 01 / 04$ & \\
\hline
\end{tabular}

Sources:

1 - National Alliance for Model State Drug Laws (www.namsdl.org) and Prescription Drug Abuse Policy System (www.pdaps.org)

2 - Prescription Drug Monitoring Program Training and Technical Assisrance Center (www.pdmpassist.org). Drugs of concern include substances that are not in the Schedules monitored and vary by state.

3 - Prescription Drug Abuse Policy System (www.pdaps.org).

4 - Davis et al. (2019b) 
B Identification Tests for Regression Discontinuity Designs 
Figure B1: Changes in other opioid related policies around the time of federal scheduling changes of HCPs and tramadol.

Panel A: Other state opioid policy changes around federal HCP up-scheduling

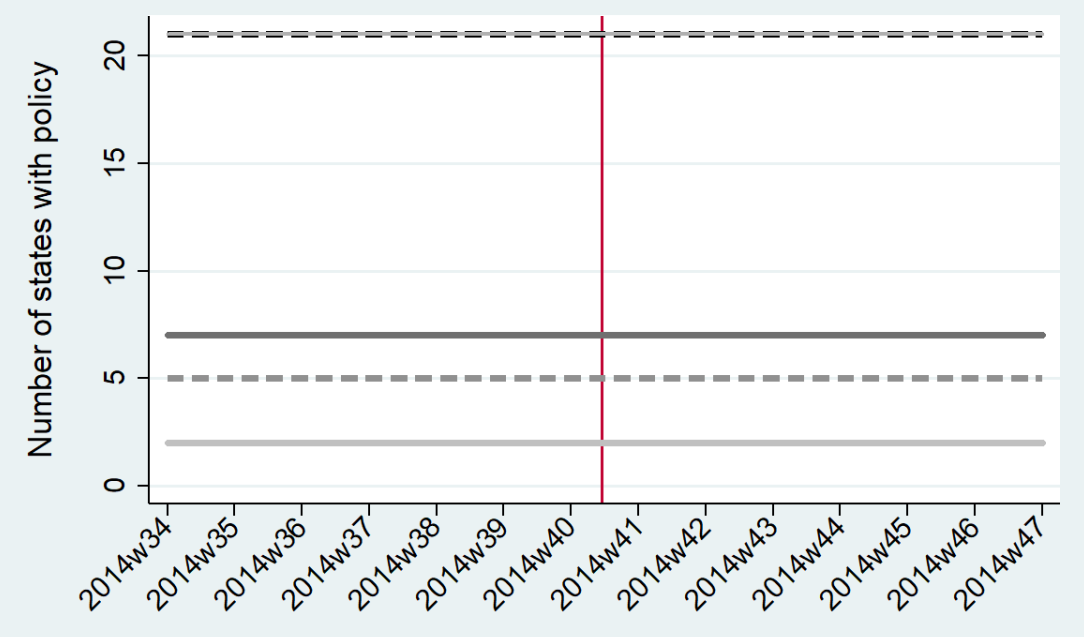

Panel B: Other state opioid policy changes around federal tramadol scheduling

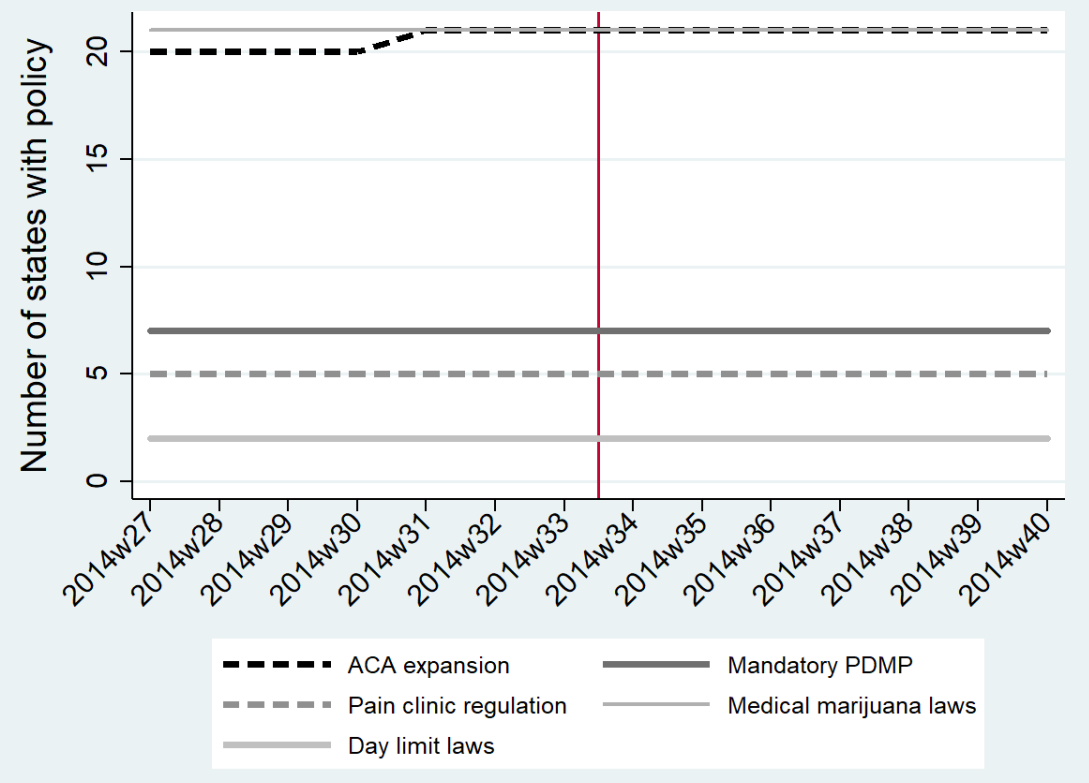

Notes: Five other opioid-related policies are considered - ACA expansions, mandatory PDMP laws, pain clinic regulations, medical marijuana laws and day limit laws (refer Appendix Table A2 for relevant dates and source of information). Panel A plots the number of states in which each policy was in effect in the 14-week window surrounding the federal up-scheduling of HCPs (2014w34-2014w47). In Panel A the vertical line represents the federal up-scheduling of HCPs on October 8, 2014. Panel $\mathrm{B}$ plots the number of states in which each policy was in effect in the 14-week window surrounding the federal initial scheduling of tramadol (2014w27-2014w40). In Panel B the vertical line represents the timing of federal initial scheduling of tramadol on August 18, 2014. 
Figure B2: Plots of relationship between bandwidth and RD estimate, with $95 \%$ confidence intervals.

\section{Panel A: HCPs}
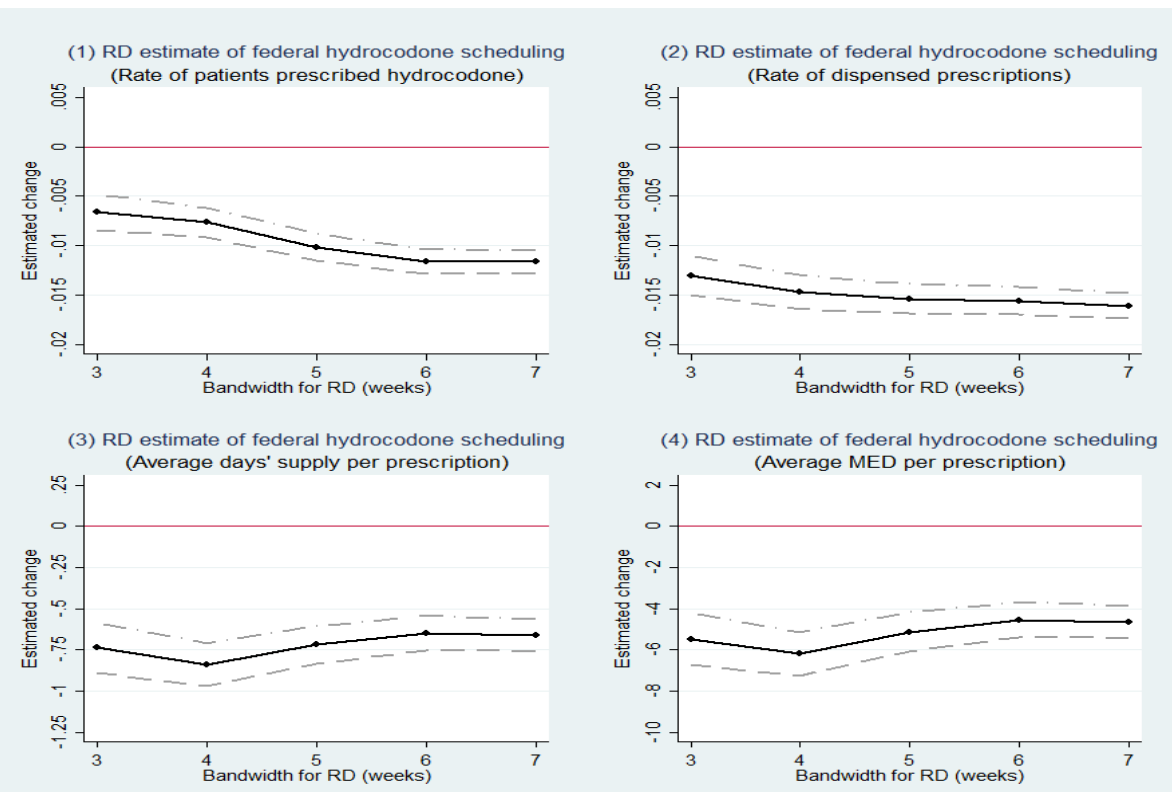

\section{Panel B: Tramadol}
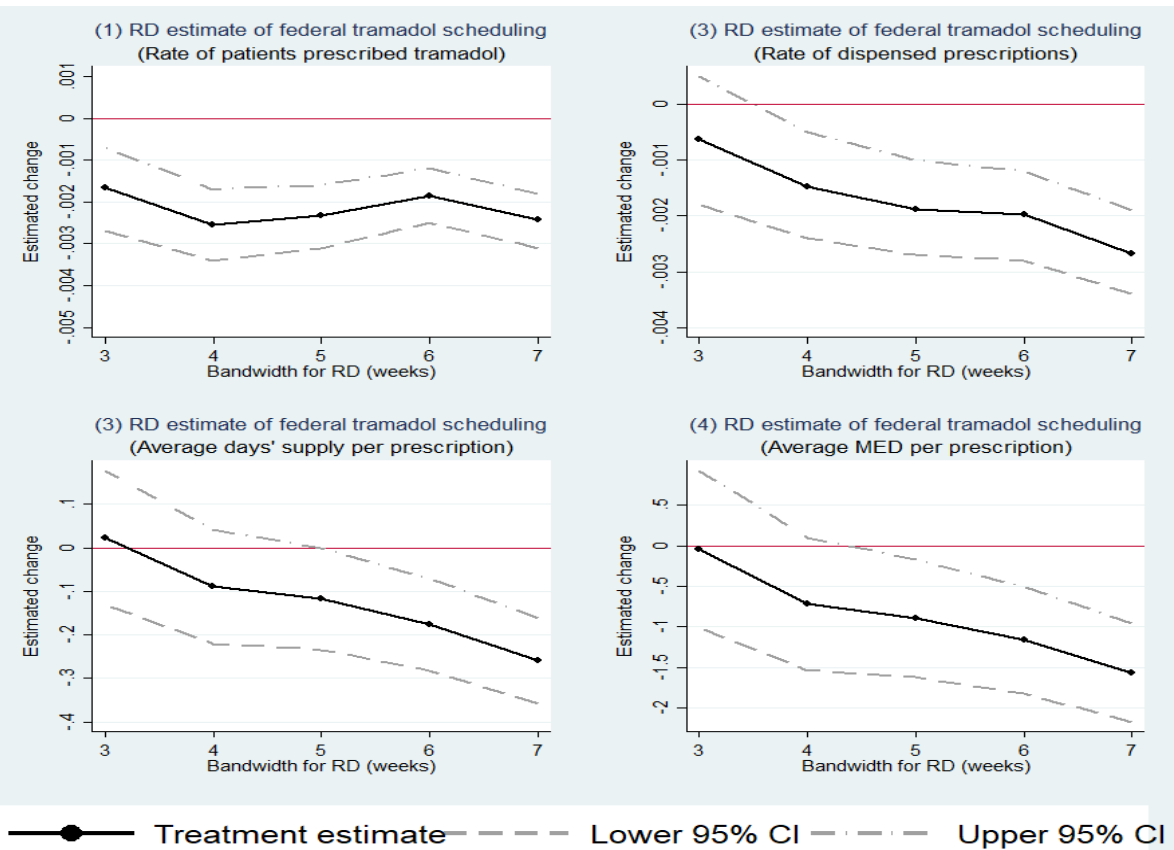

Notes: Authors' calculations based on Optum's de-identified Clinformatics ${ }^{\circledR}$ Data Mart system, a comprehensive commercial and Medicare Advantage claims database. Unit of observation is prescriber-week. Observation window is August 2014 to November 2014 (Panel A) and June 2014 to October 2014 (Panel B). Unit of observation is prescriber-year-week. Four prescription dispensing outcomes are considered for both drugs - user rates (1), prescription rates (2), average days' supply per prescription (in Days) (3), and average strength per prescription (in MED) (4). The number of total patients in the database changes throughout our study period. The data do not report the number of patients enrolled with each prescriber in every week. Therefore, rates of patients prescribed (1) and prescriptions (2) are calculated with a denominator of the total number of unique patients the prescriber prescribed (any opioid or non-opioid drug) to each week. Effect of scheduling changes from regression discontinuity estimation with $95 \%$ confidence intervals are presented for alternative bandwidths of 3-7 weeks. 


\section{Difference-in-difference treatment estimates of state initial scheduling of Tramadol}

We estimated the effect of state-level level (up)scheduling of HCPs and tramadol using a standard difference-in-difference (DD) event study that exploited the variation in timing of scheduling across states and and over time; 9 states provide variation in tramadol policy, but only one state for HCPs. The event study allows us to examine dynamic response of prescription dispensing, allows us to shed light on the equality of prescribing trends between treated and control observations in the pre-intervention time period, the underlying identifying assumption. The event study was specified as:

$$
Y_{s t}=\sum_{t} \beta_{t}((U p) \text { scheduled During } t)_{s t}+\boldsymbol{X}_{s t} \delta+\gamma_{s}+\tau_{t}+\epsilon_{s t}
$$

The key outcome $\left(Y_{s t}\right)$ represents the prescription dispensing rate in state $s$ in quarter $t$. The key independent variable is (Up)scheduled During $T_{s t}$, a vector of indicator variables equal to 1 in the year-quarter specified. The week before implementation was omitted as the reference period. $\boldsymbol{X}_{\boldsymbol{s}}$ represents a number of potential time-varying characteristics of the state that may be correlated with prescribing, including unemployment rate (Hollingsworth et al. 2017), percent of state population that is black, percent of state population that is other non-white race, percent of state population that is over age 65, percent of state population that is male, and the number of physicians, registered nurses and physician assistants per 100,000 persons in the state as a measure of provision of health care. All specifications also include state fixed effects and year-by-quarter fixed effects. Regressions are weighted by state population, and standard errors are clustered at the state level.As a sensitivity test, we also estimate a version of Model C1 with prescriber fixed effects, instead of state fixed effects.

Average effects of the new CSA regulations of HCPs and tramadol on the prescription dispensing is estimated using the coefficient on the indicator for whether the state (up)scheduled HCPs or tramadol in that quarter $\left((U p)\right.$ scheduled $\left._{s t}\right)$ in Model $\mathrm{C} 2$.

$$
Y_{s t}=\beta\left((U p) \text { scheduled }_{s t}\right)+\boldsymbol{X}_{s t} \delta+\gamma_{s}+\tau_{t}+\epsilon_{s t}
$$

The remaining variables and model specifications are identical to Model C1.

In line with our main regression discontinuity estimates, we also examined whether the new scheduling changes affected initial prescribing or if they affected subsequent refills by re-estimating Model $\mathrm{C} 1$ and Model $\mathrm{C} 2$ separately for the sample of initial prescriptions and 
refills. 
Figure C1: Event study estimates of the effect of state-level initial scheduling of tramadol on its prescribing

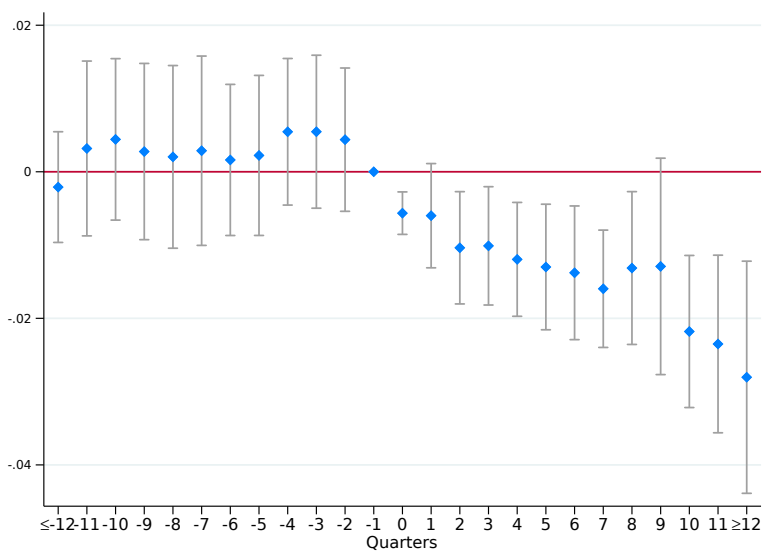

(a) Rate of patients prescribed

尺े

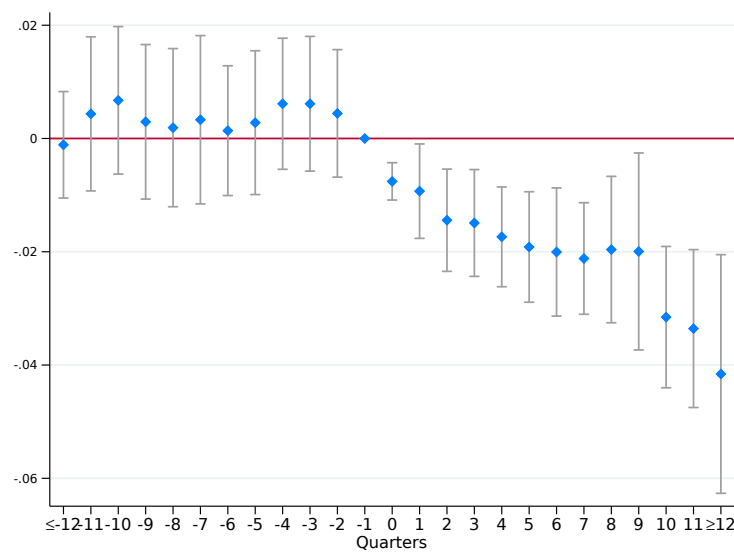

(b) Rate of dispensed prescriptions

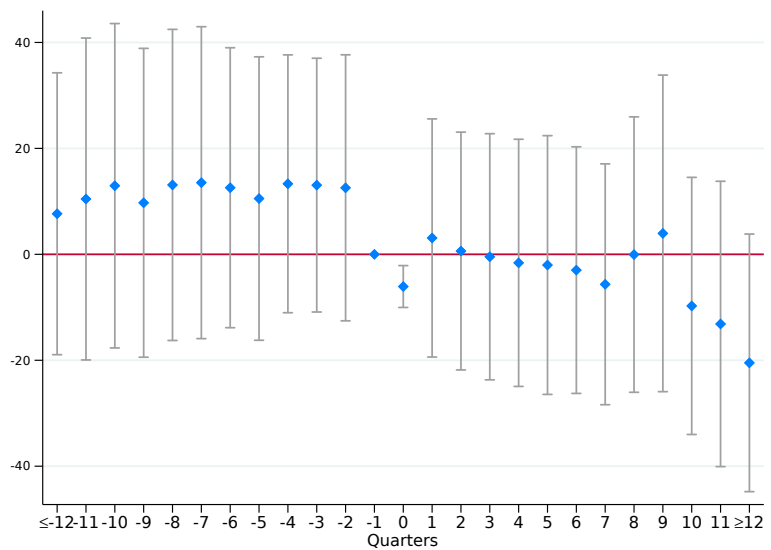

(d) Average strength per prescription (in MED)

Notes: Authors' calculations based on Optum's de-identified Clinformatics ${ }^{\circledR}$ Data Mart system, a comprehensive commercial and Medicare Advantage claims database. Sample considered - user rates (a), prescription rates (b), average days' supply per Prescription (in Days) (c) and average Strength per Prescription (in MED) (d). The number of total patients in the database changes throughout our study period. Therefore, rates of patients prescribed (1) and prescriptions (2) are calculated as the number of enrollees with tramadol claims divided by total enrollees. The quarter prior to the state-level initial scheduling of tramadol is treated as the reference period. DD event-study estimation controls for state fixed effects and quarter-year fixed effects. Time-variant controls include median income, unemployment rates, and poverty rates. Robust standard errors, clustered on state. 
Figure C2: Event study estimates of the effect of state-level initial scheduling of tramadol on its initial vs. refill prescribing

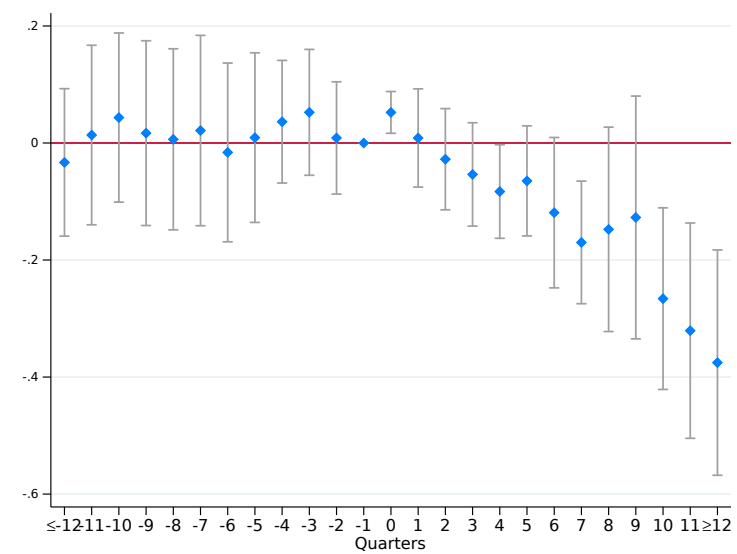

(a) Rate of initial prescriptions

ఏ)

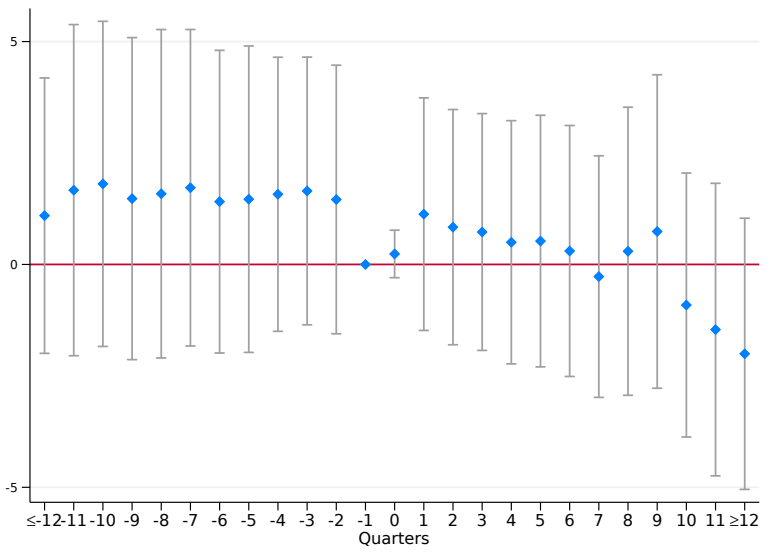

(c) Average days' supply per initial prescription

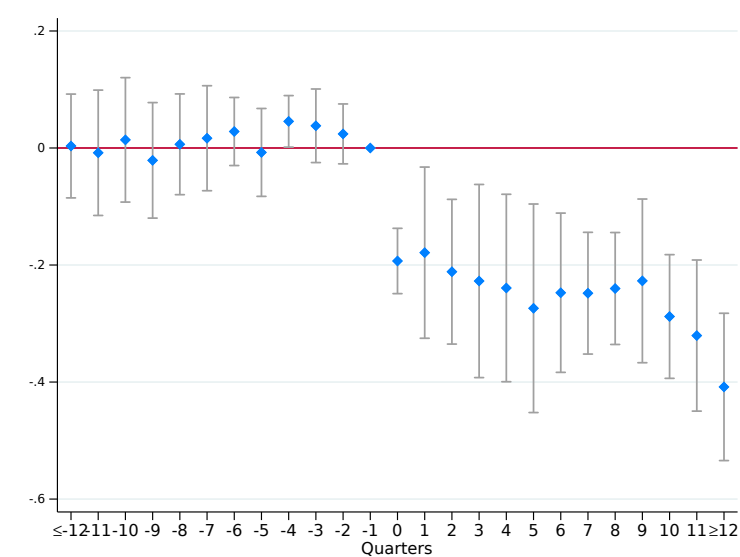

(b) Rate of refill prescriptions

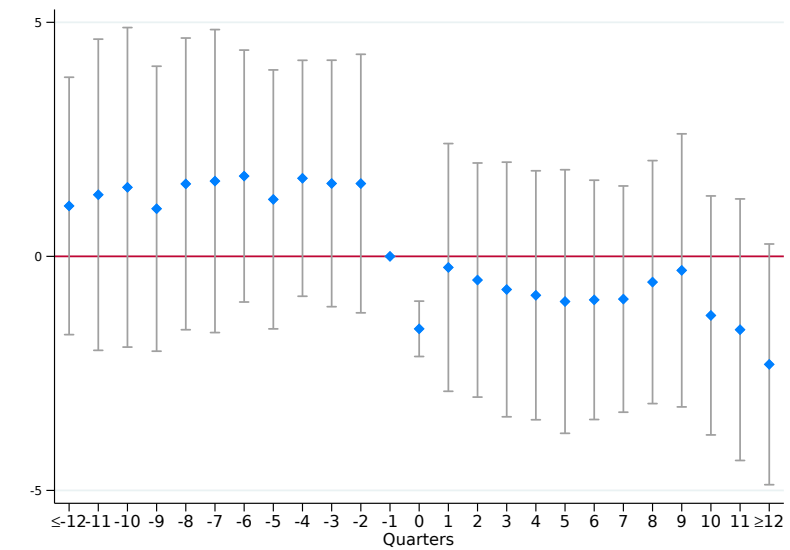

(d) Average days' supply per refill prescription Notes: Authors' calculations based on Optum's de-identified Clinformatics ${ }^{\circledR}$ Data Mart system, a comprehensive commercial and Medicare Advantage claims database. Sample
only includes the state of New York. Observation window is $2007 \mathrm{q} 1$ to $2014 \mathrm{q} 2$. Unit of observation is prescriber-quarter. 
Table C1: DD estimates: State-level initial scheduling of Tramadol

\begin{tabular}{|c|c|c|c|c|c|c|c|c|}
\hline & $(1)$ & $(2)$ & $(3)$ & $(4)$ & $(5)$ & $(6)$ & $(7)$ & (8) \\
\hline & Patients & $\mathbf{R x}$ & Days/Rx & $\mathrm{MED} / \mathrm{Rx}$ & Days(Initial) & Days(Refill) & Days/Rx(Initial) & Days/Rx(Refill) \\
\hline \multicolumn{9}{|c|}{ Panel A.Baseline model (no other state policies) } \\
\hline Post $\times$ Reschedule & $\begin{array}{r}-0.014^{* * *} \\
(0.0035)\end{array}$ & $\begin{array}{c}-0.020^{* * *} \\
(0.0047)\end{array}$ & $\begin{array}{c}-2.02^{* *} \\
(0.62)\end{array}$ & $\begin{array}{c}-10.3^{* *} \\
(3.28)\end{array}$ & $\begin{array}{c}-0.10 \\
(0.066)\end{array}$ & $\begin{array}{c}-0.23^{* * *} \\
(0.045)\end{array}$ & $\begin{array}{l}-0.79 \\
(0.51)\end{array}$ & $\begin{array}{c}-1.75^{* * *} \\
(0.38)\end{array}$ \\
\hline Dep. Variable Mean & 0.08 & 0.11 & 15.96 & 88.14 & 1.26 & 0.83 & 9.97 & 7.69 \\
\hline Dep. Variable SE & 0.20 & 0.26 & 42.26 & 261.70 & 3.80 & 3.27 & 28.92 & 27.57 \\
\hline Obs. & 8307483 & 8307483 & 8307483 & 8307483 & 8307483 & 8307483 & 8307483 & 8307483 \\
\hline R-squared & 0.02 & 0.02 & 0.02 & 0.02 & 0.01 & 0.00 & 0.02 & 0.01 \\
\hline \multicolumn{9}{|c|}{ Panel B. Control for state policies } \\
\hline \multirow[t]{2}{*}{ Post $\times$ Reschedule } & $-0.010 * *$ & $-0.015^{* *}$ & $-1.30^{*}$ & $-6.92^{*}$ & -0.039 & $-0.19 * * *$ & -0.34 & $-1.41 * * *$ \\
\hline & $(0.0035)$ & $(0.0047)$ & $(0.54)$ & $(2.84)$ & $(0.086)$ & $(0.027)$ & $(0.55)$ & $(0.24)$ \\
\hline \multirow[t]{2}{*}{ Post $\times$ Medicaid expansion } & -0.0047 & -0.0047 & -0.29 & -1.11 & -0.066 & -0.052 & -0.19 & -0.22 \\
\hline & $(0.0038)$ & $(0.0044)$ & $(1.29)$ & $(6.60)$ & $(0.053)$ & $(0.037)$ & $(0.86)$ & $(0.74)$ \\
\hline \multirow[t]{2}{*}{ Post $\times$ Mandatory PDMPs } & $-0.012^{* *}$ & $-0.016^{* * *}$ & $-2.21 * *$ & $-10.4^{* *}$ & $-0.14^{*}$ & $-0.16^{* * *}$ & $-1.09+$ & $-1.38^{* * *}$ \\
\hline & $(0.0035)$ & $(0.0045)$ & $(0.76)$ & $(3.76)$ & $(0.057)$ & $(0.030)$ & $(0.55)$ & $(0.35)$ \\
\hline \multirow[t]{2}{*}{ Post $\times$ Pain clinic laws } & $0.013^{* *}$ & $0.016^{* *}$ & 0.89 & 1.44 & $0.18^{*}$ & 0.061 & 0.90 & 0.20 \\
\hline & $(0.0047)$ & $(0.0055)$ & $(1.38)$ & $(7.03)$ & $(0.076)$ & $(0.048)$ & $(0.89)$ & $(0.70)$ \\
\hline \multirow[t]{2}{*}{ Post $\times$ Medical cannabis laws } & -0.0038 & -0.0053 & -0.28 & 0.19 & 0.0080 & -0.025 & -0.15 & -0.32 \\
\hline & $(0.0031)$ & $(0.0033)$ & $(0.75)$ & $(3.77)$ & $(0.036)$ & $(0.026)$ & $(0.50)$ & $(0.38)$ \\
\hline \multirow[t]{2}{*}{ Post $\times$ Days limits } & -0.00097 & -0.00050 & -0.48 & -2.07 & -0.088 & 0.0098 & -0.54 & 0.078 \\
\hline & $(0.0043)$ & $(0.0053)$ & $(0.70)$ & $(3.43)$ & $(0.097)$ & $(0.024)$ & $(0.71)$ & $(0.22)$ \\
\hline R-squared & 0.02 & 0.02 & 0.02 & 0.02 & 0.01 & 0.00 & 0.02 & 0.01 \\
\hline \multicolumn{9}{|c|}{ Panel C.Control for provider fixed effects } \\
\hline \multirow[t]{2}{*}{ Post $\times$ Reschedule } & $-0.012^{* *}$ & $-0.018^{* * *}$ & $-2.18^{*}$ & $-10.3^{*}$ & -0.089 & $-0.22^{* * *}$ & -0.88 & $-1.94^{* * *}$ \\
\hline & $(0.0037)$ & $(0.0051)$ & $(0.87)$ & $(4.68)$ & $(0.068)$ & $(0.054)$ & $(0.67)$ & $(0.51)$ \\
\hline R-squared & 0.46 & 0.47 & 0.64 & 0.58 & 0.43 & 0.43 & 0.56 & 0.57 \\
\hline
\end{tabular}

Notes: Authors' calculations based on Optum's de-identified Clinformatics ${ }^{\circledR}$ Data Mart system, a comprehensive commercial and Medicare Advantage claims database. Sample only includes the state of New York. Observation window is 2007q1 to 2014q2. Unit of observation is prescriber-quarter. The eight tramadol prescription dispensing outcomes are considered - user rates for all prescriptions dispensed (1), prescription rates for all prescriptions dispensed (2), average days' supply per prescription (in Days) for all prescriptions dispensed (3), average strength per prescription (in MED) for all prescriptions dispensed (4), days' supply for initial prescriptions (5), days' supply for refill prescriptions (6), average days' supply per initial prescription (in Days) (7), and average days' supply per refill prescription (in Days) (8). The number of total patients in the database changes throughout our study period. Therefore, rates of patients prescribed (1) and prescriptions (2) are calculated as the number of enrollees with tramadol claims divided by total enrollees. In baseline model (Panel 1), we control for state fixed effects and quarter-year fixed effects. Time-variant controls include median income, unemployment rates, and poverty rates (Panel 2). Robust standard errors, clustered on state, were reported in parentheses. $*$ p $<0.05, * * \mathrm{p}<0.01, * * *$ $\mathrm{p}<0.001$. Standard errors in parentheses. 
D Trends in HCP and tramadol prescribing surrounding state-level scheduling changes 
Figure D1: Trends in tramadol prescribing (2007-2017).
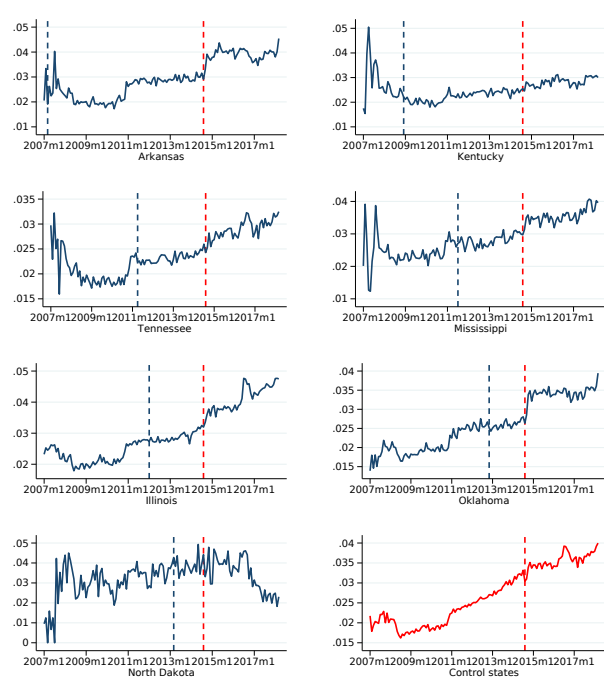

(e)
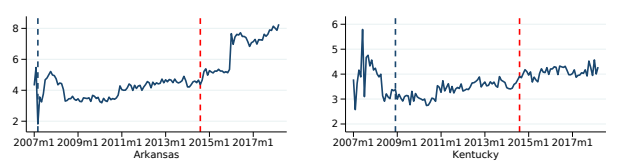

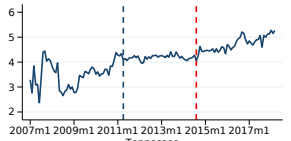
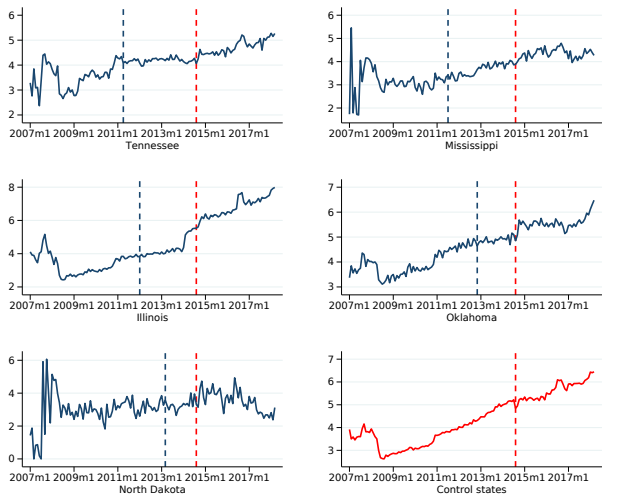

(g) Average days' supply per prescription (in days)
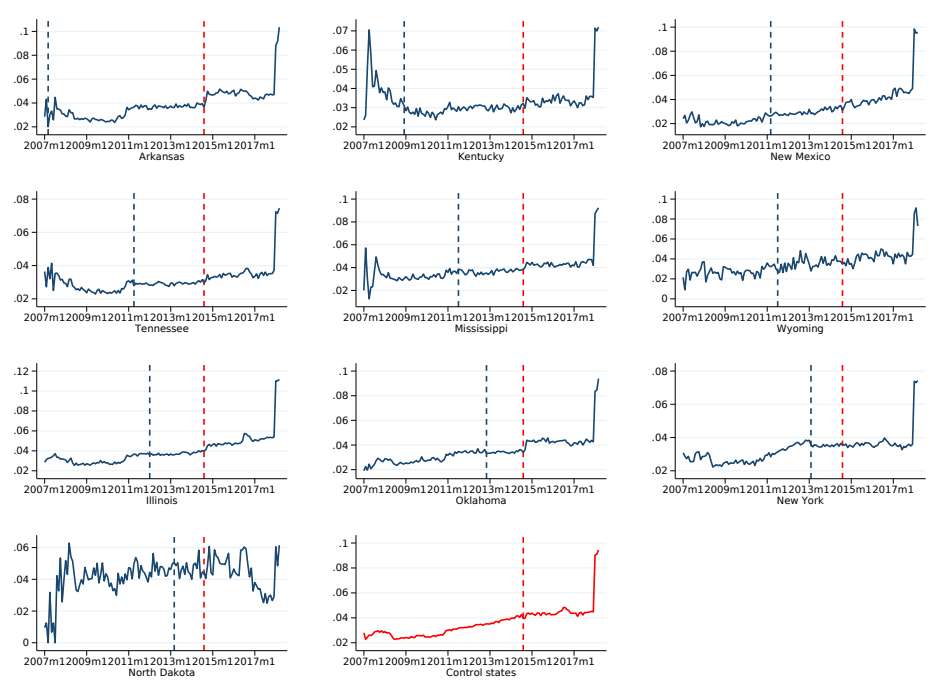

(f) Rate of dispensed prescriptions
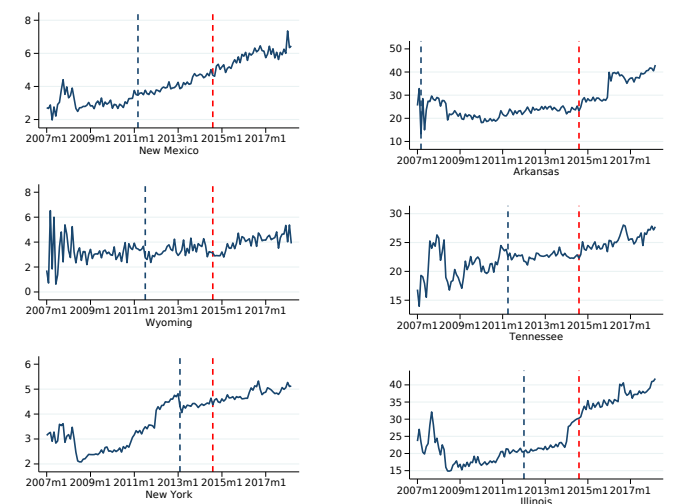

Average MED per Prescription
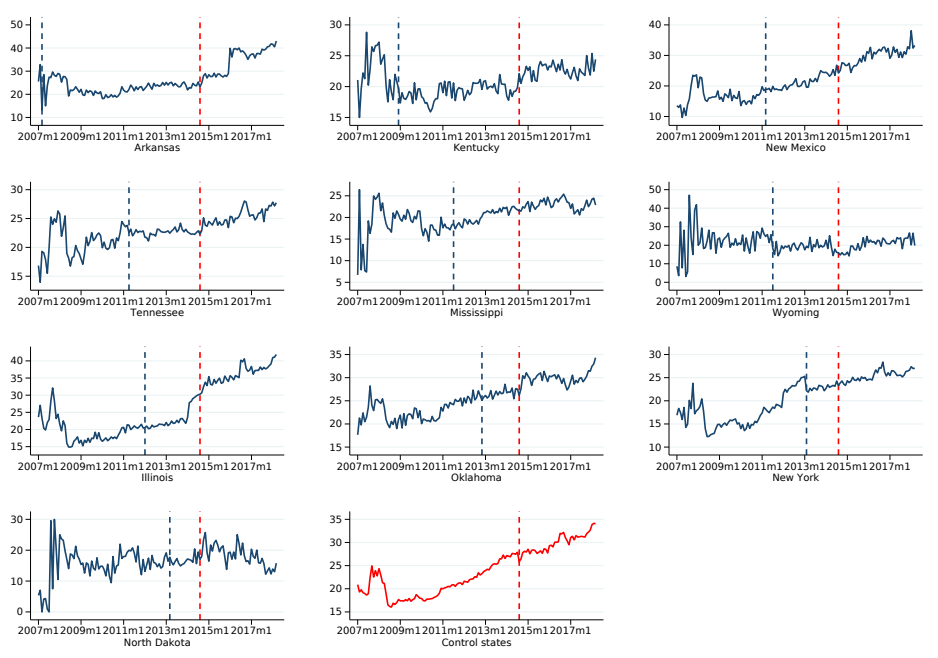

(h) Average strength per prescription (in MED) 


\section{E Checks for changes in total MED}

Figure E1: Long-term trends in prescribing of different opioid classes in OPTUM.

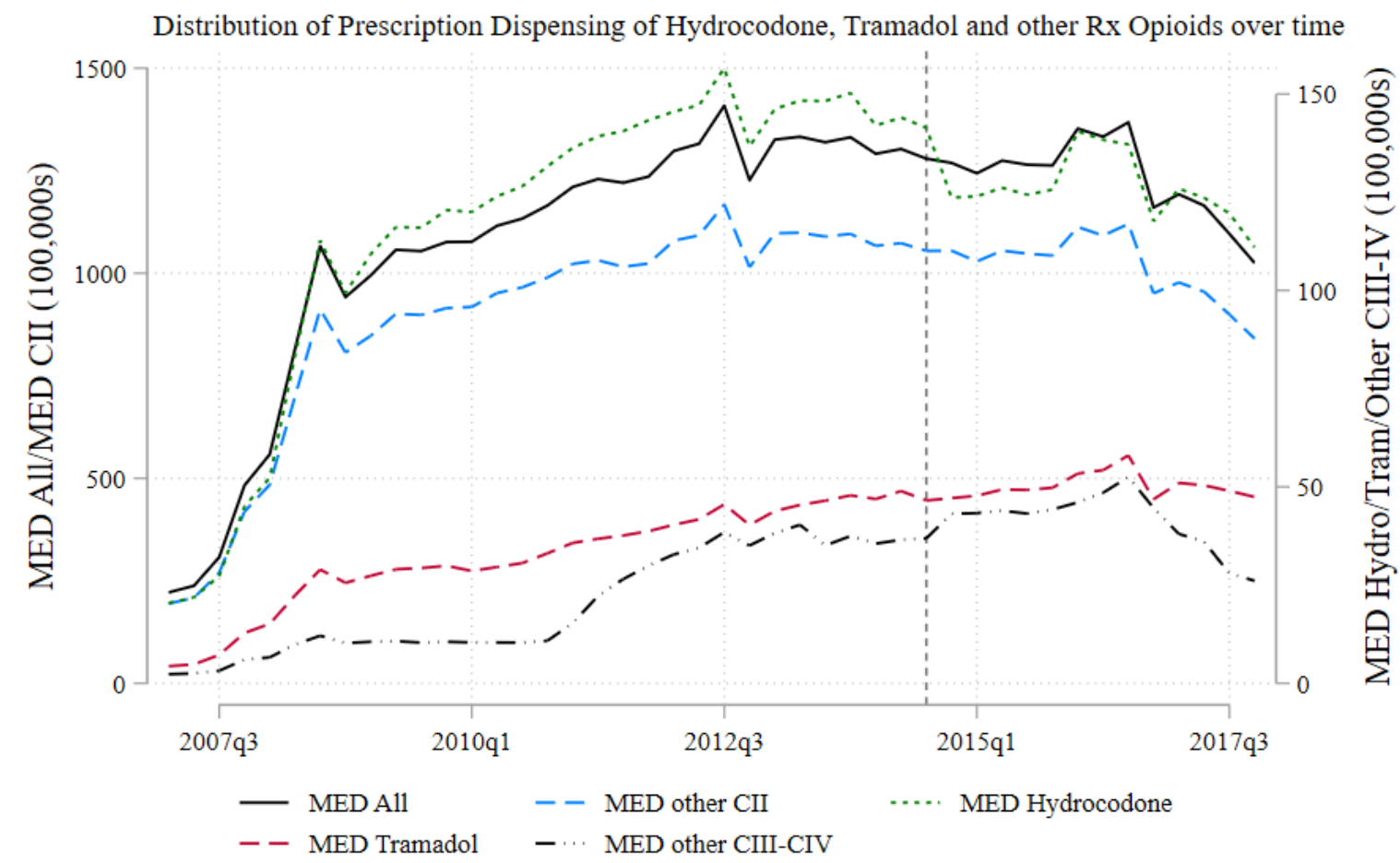

Source: OPTUM (2007q1 - 2018q1)

Notes: 
Figure E2: Aggregate Retail MME supply of HCPs, CIII-CIV opioids (select codeine products and buprenorphine for pain), other CII opioids (excluding HCPs) and All Rx Opioids per week, 2011-2014 (millions)
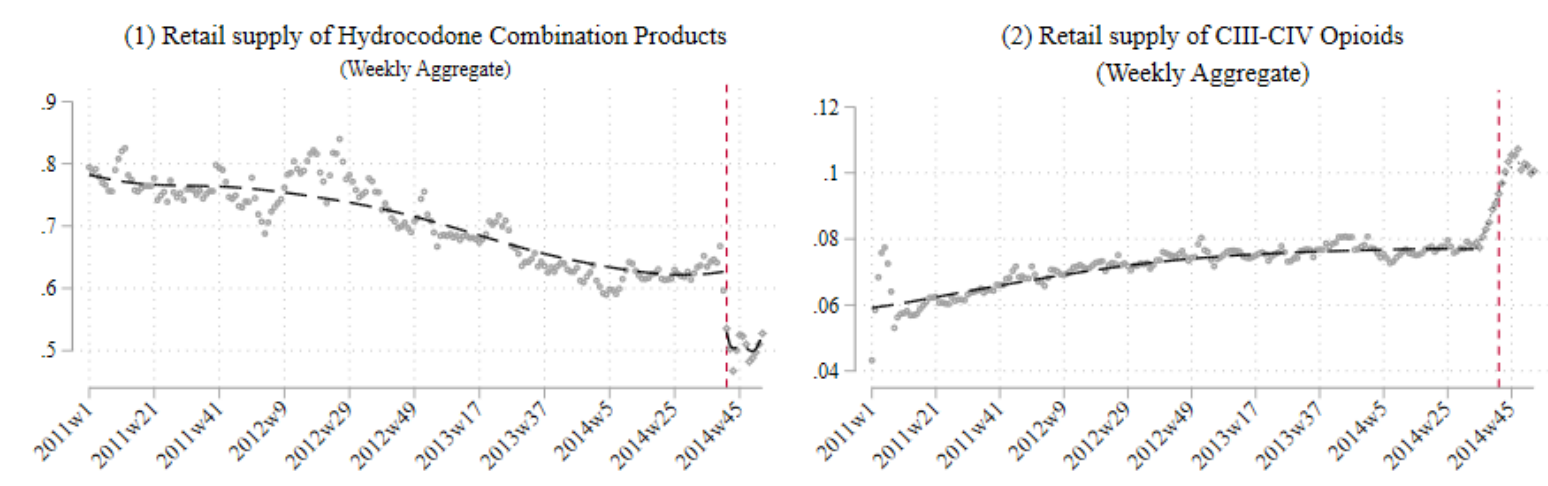

(3) Retail supply of other CII Opioids
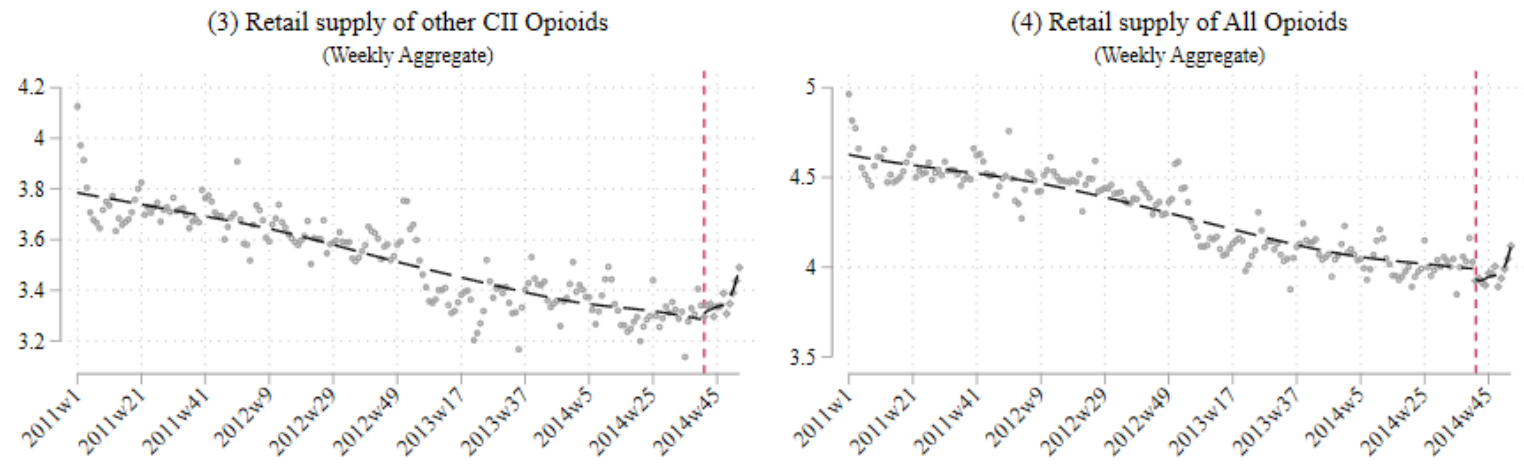

Source: Transactional ARCOS (2011w1 - 2014w52)

Red vertical line depicts federal hydrocodone upscheduling

Notes:

Table E1: RD estimates: Impact of federal up-scheduling of HCPs on opioid prescribing in Transactional ARCOS sample.

(1)

(3)

MME Hydro CP MME Codeine/bup pain MME Other CII MME All

\begin{tabular}{lcccc}
\hline Impact rescheduling & $-23.939^{* *}$ & 0.9716 & -64.677 & -87.644 \\
& $(10.5725)$ & $(2.0314)$ & $(55.1342)$ & $(64.7989)$ \\
Trend after & -1.9846 & $0.7120^{* * *}$ & 10.494 & 9.2214 \\
& $(1.3115)$ & $(0.2520)$ & $(6.8392)$ & $(8.0380)$ \\
\hline Observations & 42709 & 42709 & 42709 & 42709 \\
Baseline DV mean & 201.95 & 28.460 & 1085.9 & 1316.3 \\
\hline
\end{tabular}

Notes: Authors' calculations based on transactional ARCOS data released on order of the United States District Court Northern District of Ohio Eastern Division following the Natonal Prescription Opiate Litigation (Case No. 1:17-MD-2804, UNITED STATES DISTRICT COURT NORTHERN DISTRICT OF OHIO EASTERN DIVISION). Observation window is 2014w34 to 2014w47. HCPs were federally up-scheduled from CIII to CII in 2014w40. Unit of observation is county-week-year. Changes in aggregate MME supplied of 4 different opioid drug classes for retail class - HCPs (1), CIII-CIV tracked in ARCOS (select codeine products and buprenorphine products for pain) (2), other CII opioids excluding HCPs (3) and all opioids (4). ${ }^{*} \mathrm{p}<0.05,{ }^{* *} \mathrm{p}<0.01,{ }^{* * *} \mathrm{p}<0.001$. Standard errors in parentheses. 
Figure E3: Trends in prescribing of different opioid classes in SDUD.

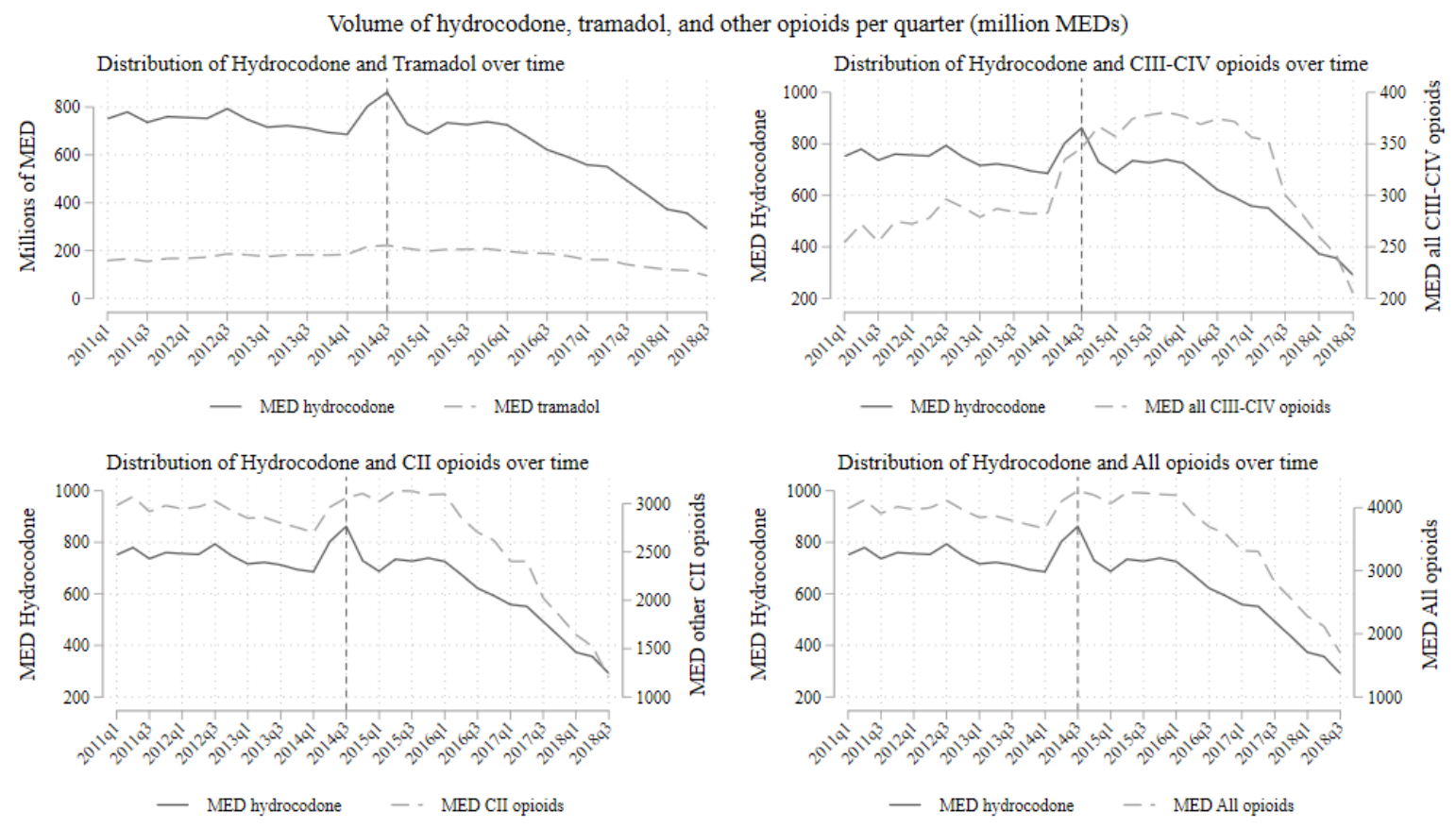

Source: SDUD (2011Q1 - 2018Q3)

Notes: 
Table E2: RD estimates: Impact of federal up-scheduling of HCPs on opioid prescribing in SDUD sample.

\begin{tabular}{lrcccccc}
\hline & \multicolumn{5}{c}{ Total log MED } \\
\cline { 2 - 8 } & hydrocodone & tramadol & Other CIII-CIV opioids & Other C2 opioids & All CIII-CIV & All CII & All opioids \\
\hline Estimate & -0.1681 & -0.09129 & 0.1422 & -0.02082 & -0.01304 & -0.05614 & -0.05124 \\
& $(0.2792)$ & $(0.2660)$ & $(0.2733)$ & $(0.2555)$ & $(0.2632)$ & $(0.2529)$ & $(0.2524)$ \\
Dep. variable mean & 15.260 & 13.980 & 13.270 & 16.690 & 14.410 & 16.950 & 17.030 \\
Dep. variable SD & $(1.3900)$ & $(1.3200)$ & $(1.3400)$ & $(1.2700)$ & $(1.3100)$ & $(1.2500)$ & $(1.2500)$ \\
\hline $\mathrm{N}$ & 312 & 312 & 312 & 312 & 312 & 312 & 312 \\
\hline
\end{tabular}

Notes: Authors' calculations based on SDUD sample. Observation window is 20013q3 to 2014q2. Unit of observation is state-quarter. Changes in prescribing of 8 different opioid drug classes - HCPs (1), tramadol (2), other CIII-CIV opioids excluding tramadol (3), other CII opioids excluding HCPs (4), all CIII-IV opioids (5), all CII opioids (6) and all opioids (7) - are measured as log total MED. ${ }^{*} \mathrm{p}<0.05,{ }^{* *} \mathrm{p}<0.01,{ }^{* * *} \mathrm{p}<0.001$. Standard errors in parentheses. 